\title{
Experiential appreciation as a pathway to meaning in life
}

\author{
Jinhyung Kim ${ }^{1}$, Patricia Holte' ${ }^{2}$, Frank Martela $\oplus^{3}$, Colin Shanahan², Zhanhong Li ${ }^{4}{ }^{4}$, Hong Zhang ${ }^{5}$,

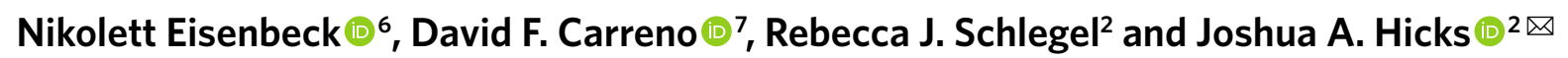

\begin{abstract}
A key research program within the meaning in life (MIL) literature aims to identify the key contributors to MIL. The experience of existential mattering, purpose in life and a sense of coherence are currently posited as three primary contributors to MIL. However, it is unclear whether they encompass all information people consider when judging MIL. Based on the ideas of classic and contemporary MIL scholars, the current research examines whether valuing one's life experiences, or experiential appreciation, constitutes another unique contributor to MIL. Across seven studies, we find support for the idea that experiential appreciation uniquely predicts subjective judgements of MIL, even after accounting for the contribution of mattering, purpose and coherence to these types of evaluations. Overall, these findings support the hypothesis that valuing one's experiences is uniquely tied to perceptions of meaning. Implications for the incorporation of experiential appreciation as a fundamental antecedent of MIL are discussed.
\end{abstract}

\section{I/} magine a music lover sitting in the concert hall, while the most noble measures of his favorite symphony resound in his ears. He feels that shiver of emotion which we experience in the presence of the purest beauty. Suppose now that at such a moment we should ask this person whether his life has meaning. He would have to reply that it had been worthwhile living if only to experience this ecstatic moment." (ref. ${ }^{1}$, p. 43 )

What do people mean when they say their lives are meaningful? Although scholars propose that judgements of meaning in life (MIL) are primarily derived from a few key perceptions ${ }^{2-6}$, the majority of research on MIL has assessed judgements of general meaning to understand this abstract experience ${ }^{7}$. These measures typically rely on face valid items that assess subjective evaluations of meaning, thus leaving individuals to rely on their intuition about what meaning actually means. This body of research has empirically identified many theoretically relevant variables that influence subjective judgements of $\mathrm{MIL}^{8}$, and hundreds of studies have shown that MIL judgements predict some of the most valued outcomes in life ${ }^{9-17}$

In an effort to better understand the construct, scholars have recently proposed tripartite models of $\mathrm{MIL}^{3-5}$. According to these models, the experience of meaning in life is derived from a sense of coherence, purpose and mattering. Coherence represents the extent to which the individual feels that aspects of their life fit together in a comprehensible manner ${ }^{18}$. Purpose is the extent to which the individual perceives their life as being directed and motivated by valued goals ${ }^{19-21}$. Finally, existential mattering reflects "the degree to which individuals feel that their existence is of significance, importance, and value in the world" (ref. ${ }^{4}$, p. 212). These three contributors are believed to be so intertwined with the experience of MIL that many scholars argue that they represent facets of MIL itself ${ }^{3-5}$. Whilst empirical investigations have yet to rigorously test the structure of MIL, data have revealed that each of these variables shares robust, and unique, links with self-reports of $\mathrm{MIL}^{3}$.
The three components of these tripartite models of MIL are consistent with the idea that meaning emerges from the human mind's ability to "connect things"18. Applied to one's own life, MIL emerges when one feels that their life is connected in valuable ways to. Meaning, as such, is thus about a general sense of value and significance in life emerging from feeling that one's life is connected in ways that generate value. When we understand MIL like this, we can also understand how the three proposed facets are related to it. Coherence, as noted above, is about being able to connect the dots in one's life and make sense of it. Instead of chaotic and unrelated, various dimensions of one's life are connected into meaningful structures that help one understand what is happening. Purpose, in turn, is about connecting one's present actions with valuable goals in the future. Instead of a bunch of arbitrary and unconnected actions, having a future-oriented purpose connects these actions to a meaningful and purposeful whole. Mattering is then about feeling that one's life is connected to something bigger. That is, despite the grandness of the universe, one's life somehow connects and contributes to this world beyond oneself. Instead of inconsequential and isolated, one's life has a role to play in the grander scheme of things. These theorized facets thus represent three primary cues that give rise to a feeling of deep connection, or meaning, in life.

In this paper, we argue that appreciating one's experiences, or experiential appreciation (EA), represents another fundamental contributor to the experience of MIL. The quote at the beginning of this paper illustrates a poignant example of this path to meaning. Like Frankl, we believe that valuing one's experiences fosters a sense of MIL that can be distinct from feelings of coherence, purpose or mattering. In this case, MIL is felt simply by appreciating the intrinsic beauty of the moment. In this paper, we elaborate on the concept of EA and why we think it is as important to the experience of MIL as coherence, purpose or mattering.

According to Frankl ${ }^{1}$, three types of values lay the groundwork for a meaningful existence. First, creative values help the individual

'Department of Psychology, Sogang University, Seoul, Republic of Korea. ${ }^{2}$ Department of Psychological and Brain Sciences, Texas A\&M University, College Station, TX, USA. ${ }^{3}$ Department of Industrial Engineering and Management, Aalto University, Espoo, Finland. ${ }^{4}$ Department of Psychology, Tsinghua University, Beijing, China. ${ }^{5}$ Department of Psychology, Nanjing University, Nanjing, China. ${ }^{6}$ Department of Psychology, Universidad de Sevilla, Sevilla, Spain. 7Department of Psychology, Universidad de Almería, Almería, Spain. $₫ e$-mail: joshua.hicks@tamu.edu 
do or create something of personal value, often in the service of oth$\mathrm{ers}^{22}$. Second, attitudinal values help the individual take a more positive stance towards a negative situation, helping them, for example, "find meaning in suffering". Finally, experiential values allow one to detect and appreciate the beauty in life itself. In line with this latter perspective, we see EA as being about valuing and appreciating one's life experiences. It is the kind of meaning we might find in listening to music or appreciating a piece of art or nature, and the kind of meaning even children can experience, as de Muijnck ${ }^{23}$ notes: "It is the kind of meaning that is in their Mom's face, in their comfort object or their toys, in the rocking on Uncle's knee". EA is thus about being able to appreciate "the meaning potential of the moment" (ref. ${ }^{22}$, p. 13). As Frankl asserts, "man not only finds his life meaningful through his deeds, his works, and his creativity, but also through his experiences" (ref. ${ }^{1}$, p. 14).

Overall, MIL comes from both "what we give to life (in terms of our creative works)" and "what we take from the world (in terms of our experiencing values)" (ref. ${ }^{24}$, p. 14), from both constructing meaning and detecting meaning ${ }^{25}$. Mattering and purpose are clearly about constructing meaning and giving to the world, but research has shown that people also passively detect meaning ${ }^{25}$ and that their judgements about MIL are sensitive to subtle characteristics of the surrounding environment ${ }^{26}$. Thus, the inclusion of EA as a core indicator of MIL will balance our accounts of meaning by also emphasizing the meaning that is extracted from the world itself. Like the other contributors to MIL, EA is about connecting. It is about the person feeling connected to the present moment and being able to appreciate the value within it. Instead of one's life just passing by uneventfully and trivially, one feels strongly rooted and present in one's experiences and finds value in them.

Note that, whilst coherence, purpose and mattering are sometimes discussed as different meanings of meaning ${ }^{5}$, here we follow previous empirical examinations $s^{3,4}$ in treating these variables as potential proximal cues, or indicators, that one's life is meaningful. As proximal cues, we believe that these four variables have a direct influence on subjective judgements of MIL. Whilst people may possess many general (for example, religious faith) and idiosyncratic sources of meaning, we believe that the influence of each of these antecedents on global MIL judgements flows through coherence, purpose, mattering and EA. For example, parenthood is theorized to increase perceptions of meaning for many parent $\mathrm{s}^{27,28}$. Why should parenthood lead to increased MIL? One reason is that it provides the parent with clear direction and aims, leading to purpose. Raising a child may also lead to the perception that one is influencing the child's psychosocial development (that is, one's actions matter to the child). Many times, however, parenthood feels meaningful simply because of the intrinsic value detected in the experience, such as the feeling one gets when noticing a feature of their child's personality emerge for the first time or observing the innocence of their child awkwardly interacting with a new playmate. When deciding whether one's life is meaningful, we believe that each of these factors can serve as a proximal cue that leads to an affirmative conclusion.

The current project aims to test the idea that EA is uniquely tied to general judgements of MIL. Across studies, we followed the approach of Costin and Vignoles ${ }^{3}$ to test the importance of each contributor of MIL to global evaluations of meaning by controlling for other components in each primary analysis. The goal of this approach is to demonstrate that EA is not redundant with other elements of the tripartite model of meaning.

In study 1, we used a large previously collected dataset to perform an initial test of our hypotheses regarding the importance of EA to the experience of MIL. Specifically, we tested whether coping with the initial stages of the coronavirus disease 2019 (COVID-19) pandemic through life appreciation would predict general MIL over and above coping strategies related to coherence, purpose and mattering. As is often the case with an archival approach, this dataset does not include 'perfect' measures of either EA or other indicators of meaning. However, this dataset included proxy measures for all constructs, allowing us to examine a 'proof of concept' test of our idea that EA would predict MIL above coherence, purpose and mattering.

Study 2 was a cross-sectional correlational study conducted using two different samples designed to test the idea that EA uniquely predicts MIL using an established measure of meaning. We also used this as an opportunity to develop a measure of EA.

Study 3 was a daily diary study designed to assess whether the four potential components of meaning experienced during a specific day predicted MIL at the end of the day. We predicted that daily levels of EA would predict daily experiences of MIL and that this relationship would exist over and above the influence of daily levels of mattering, purpose and coherence.

Participants in study 4 were first asked to recall the most meaningful event or experience of the past week and keep that event in mind throughout the survey. They then responded to a variety of questions about the event and MIL. We predicted that ratings of EA of the event would be higher than ratings of how the event influenced the other indicators of meaning. We further predicted that the amount of EA experienced would contribute to the perception that the event influenced one's overall MIL controlling for mattering, purpose, coherence and mood.

In studies 5 and 6 , we aimed to induce a heightened state of EA by having people view an awe-inspiring video. According to many theorists ${ }^{29}$, appreciation of the natural beauty of the world is an intrinsically valuable experience that should promote a sense of appreciation for most people. We predicted that participants induced to experience awe in nature (relative to participants in a neutral control condition) would experience a heightened state of EA and, in turn, more MIL. We further predicted that this pattern would exist over and above the influence of other known indicators of meaning. We pre-registered our method, data analytical plan and hypotheses for study 6 at https://aspredicted.org/d8p5q.pdf.

Finally, participants in study 7 were asked to write about either a recent experience they greatly appreciated or a common place they recently visited. We predicted that people in the EA condition would report that the experience contributed more to their event-specific MIL compared with those in the control condition. Importantly, we further predicted that the amount of EA experienced in the event would uniquely mediate the relationship between the condition and event-specific MIL. Our study design and specific predictions were preregistered at https://aspredicted.org/pa5s6.pdf.

In many of our analyses, we control for state positive affect (PA) and negative affect (NA). This data analytical technique is consistent with recent empirical articles on the tripartite model ${ }^{3}$. This approach is also consistent with work suggesting that mood, especially PA, functions as another primary cue that life is meaningful ${ }^{2,30-32}$.

\section{Results}

Study 1. A regression analysis was conducted to test the unique contribution of coping through life appreciation on MIL. In line with our predictions, life appreciation significantly predicted MIL over and above the other three components of MIL and covariates. Coherence, purpose, mattering and both covariates also significantly predicted MIL (Extended Data Fig. 1).

Study 2. All EA items as well as the tripartite MIL components with factor loadings derived from the confirmatory factor analysis are presented in Table 1 (Extended Data Fig. 2; see Methods for details). Extended Data Fig. 3 shows the correlations for all variables of interest. To demonstrate the contribution of EA to global MIL, crisis of meaning and COVID-19-related stress, we conducted a series of regression analyses with latent variables using a structural equation model (SEM) in Mplus 
Table 1 | Confirmatory factor analysis with EA, mattering, purpose and coherence in study 2

\begin{tabular}{|c|c|c|c|c|}
\hline \multirow[b]{2}{*}{ Factor and item } & \multicolumn{2}{|c|}{ Sample A } & \multicolumn{2}{|c|}{ Sample B } \\
\hline & Internal reliability & $\begin{array}{l}\text { Factor } \\
\text { loading }\end{array}$ & Internal reliability & Factor loading \\
\hline I have great appreciation for the beauty of life. & & 0.76 & & 0.84 \\
\hline I take great interest in my daily activities. & & 0.65 & & 0.69 \\
\hline I appreciate a wide variety of experiences. & & 0.66 & & 0.73 \\
\hline I tend to find myself deeply engaged in conversations with other people. & & 0.60 & & - \\
\hline Mattering & 0.84 & & 0.83 & \\
\hline Given the vastness of the universe, my life does not matter. ${ }^{a}$ & & 0.76 & & 0.79 \\
\hline $\begin{array}{l}\text { Whether my life ever existed matters even in the grand scheme of } \\
\text { the universe. }\end{array}$ & & 0.50 & & - \\
\hline I don't know what I am trying to accomplish in life. ${ }^{a}$ & & 0.59 & & 0.68 \\
\hline I have a good sense of what I am trying to accomplish in life. & & 0.79 & & 0.79 \\
\hline I have certain life goals that compel me to keep going. & & 0.73 & & 0.79 \\
\hline I don't have compelling life goals that keep me going. ${ }^{a}$ & & 0.64 & & - \\
\hline Coherence & 0.73 & & 0.62 & \\
\hline I can't make sense of events in my life. ${ }^{a}$ & & 0.56 & & 0.56 \\
\hline I can make sense of the things that happen in my life. & & 0.65 & & 0.81 \\
\hline Looking at my life as a whole, things seem clear to me. & & 0.71 & & - \\
\hline My life feels like a sequence of unconnected events. ${ }^{\text {a }}$ & & 0.50 & & 0.82 \\
\hline
\end{tabular}

Note. Sample A: $n=986$; sample B: $n=296$. ${ }^{2}$ Reverse coded. Factor loadings are standardized values.

(version 8.0$)^{33}$. The latent variables were defined by either individual items (for example, EA) or item parcels (for example, PA) ${ }^{34}$. Each SEM included EA, mattering, purpose, coherence, PA and $\mathrm{NA}$ as predictors.

Sample A. We first conducted a SEM predicting global MIL, which revealed a good model fit $\left(\chi^{2}(279)=2,064.53, P<0.001\right.$, root mean square error of approximation (RMSEA) $=0.064(90 \%$ confidence interval (CI) 0.061-0.067), comparative fit index (CFI) 0.933, standardized root mean squared residual (SRMR) 0.044). As expected, EA uniquely predicted global MIL $(B=0.22$, s.e. $0.05, P<0.001$, 95\% CI 0.13-0.31), whilst all other predictors significantly predicted global MIL $(B=0.44$, s.e. $0.03, P<0.001,95 \%$ CI $0.39-0.50$ for mattering; $B=0.32$, s.e. $0.04, P<0.001$, $95 \%$ CI $0.20-0.44$ for purpose; $B=-0.19$, s.e. $0.05, P<0.001,95 \%$ CI -0.28 to -0.10 for NA) except for coherence $(B=-0.13$, s.e. $0.09, P=0.17,95 \%$ CI -0.31 to 0.05$)$ and $\mathrm{PA}(B=0.07$, s.e. $0.04, P=0.077,95 \% \mathrm{CI}-0.01$ to 0.14 ) (Fig. 1a).

Next, we ran the same SEM with crisis of meaning as a dependent variable. The data fitted the model well $\left(\chi^{2}(323)=1,513.00\right.$, $P<0.001$, RMSEA 0.05 (90\% CI 0.048-0.053), CFI 0.961, SRMR $0.043)$. Similarly, EA significantly predicted crisis of meaning $(B=-0.11$, s.e. $0.06, P=0.05,95 \%$ CI -0.23 to -0.001$)$, which was also significantly predicted by mattering $(B=-0.30$, s.e. 0.03 , $P<0.001,95 \%$ CI -0.37 to -0.24$)$, purpose $(B=-0.34$, s.e. 0.08 , $P<0.001,95 \% \mathrm{CI}-0.49$ to -0.20$)$, PA $(B=-0.26$, s.e. $0.05, P<0.001$, $95 \% \mathrm{CI}-0.35$ to -0.17$)$ and NA $(B=0.45$, s.e. $0.06, P<0.001,95 \%$ CI $0.34-0.56)$ but not by coherence $(B=0.09$, s.e. $0.12, P=0.45,95 \%$ $\mathrm{CI}-0.14$ to 0.31 ), as in the SEM for global MIL (Fig. 1b).
Sample $B$. As for sample A, we ran a SEM predicting global MIL, which yielded a good model fit $\left(\chi^{2}(208)=493.19, P<0.001\right.$, RMSEA 0.068 (90\% CI 0.060-0.076), CFI 0.935, SRMR 0.054). Consistently, EA significantly predicted global MIL $(B=0.12$, s.e. $0.05, P=0.013$, $95 \%$ CI $0.03-0.21)$, which was also predicted by mattering $(B=0.36$, s.e. $0.04, P<0.001,95 \%$ CI $0.28-0.45)$, purpose $(B=0.16$, s.e. 0.05 , $P=0.004,95 \%$ CI $0.05-0.26)$ and, different from sample A, coherence $(B=0.15$, s.e. $0.06, P=0.007$, 95\% CI $0.04-0.26)$. PA and NA did not significantly predict global MIL $(B=0.04$, s.e. 0.06 , $P=0.496$, 95\% CI $0.13-0.31$ for PA; $B=-0.09$, s.e. $0.05, P=0.085$, 95\% CI 0.13-0.31 for NA; Fig. 2a).

Finally, we conducted a SEM predicting COVID-19-related stress. The latent variables for COVID-19-related stress were defined with three item parcels. The model showed a good fit $\left(\chi^{2}(187)=397.87\right.$, $P<0.001$, RMSEA 0.062 (90\% CI 0.053-0.070), CFI 0.949, SRMR $0.057)$. In line with our predictions, EA significantly predicted fewer COVID-19-related stress symptoms $(B=-0.19$, s.e. $0.07, P=0.003$, $95 \% \mathrm{CI}-0.32$ to -0.07$)$, which was also predicted by mattering $(B=-0.10$, s.e. $0.05, P=0.033,95 \% \mathrm{CI}-0.19$ to -0.01 ) (Fig. $2 \mathrm{~b})$. NA significantly predicted greater COVID-19-related stress symptoms ( $B=0.59$, s.e. $0.07, P<0.001,95 \%$ CI $0.45-0.72)$. Whilst coherence was not a significant predictor $(B=-0.08$, s.e. $0.08, P=0.36,95 \%$ CI -0.22 to 0.08 ), unexpectedly, purpose and PA predicted greater COVID-19-related stress symptoms $(B=0.17$, s.e. $0.07, P=0.016$, $95 \%$ CI $0.03-0.30$ for purpose; $B=0.18$, s.e. $0.08, P=0.016,95 \%$ CI 0.03-0.33 for PA).

Study 3. To analyse the within-person correlations, we calculated within-person deviation scores centred around within-person 
$\mathbf{a}$

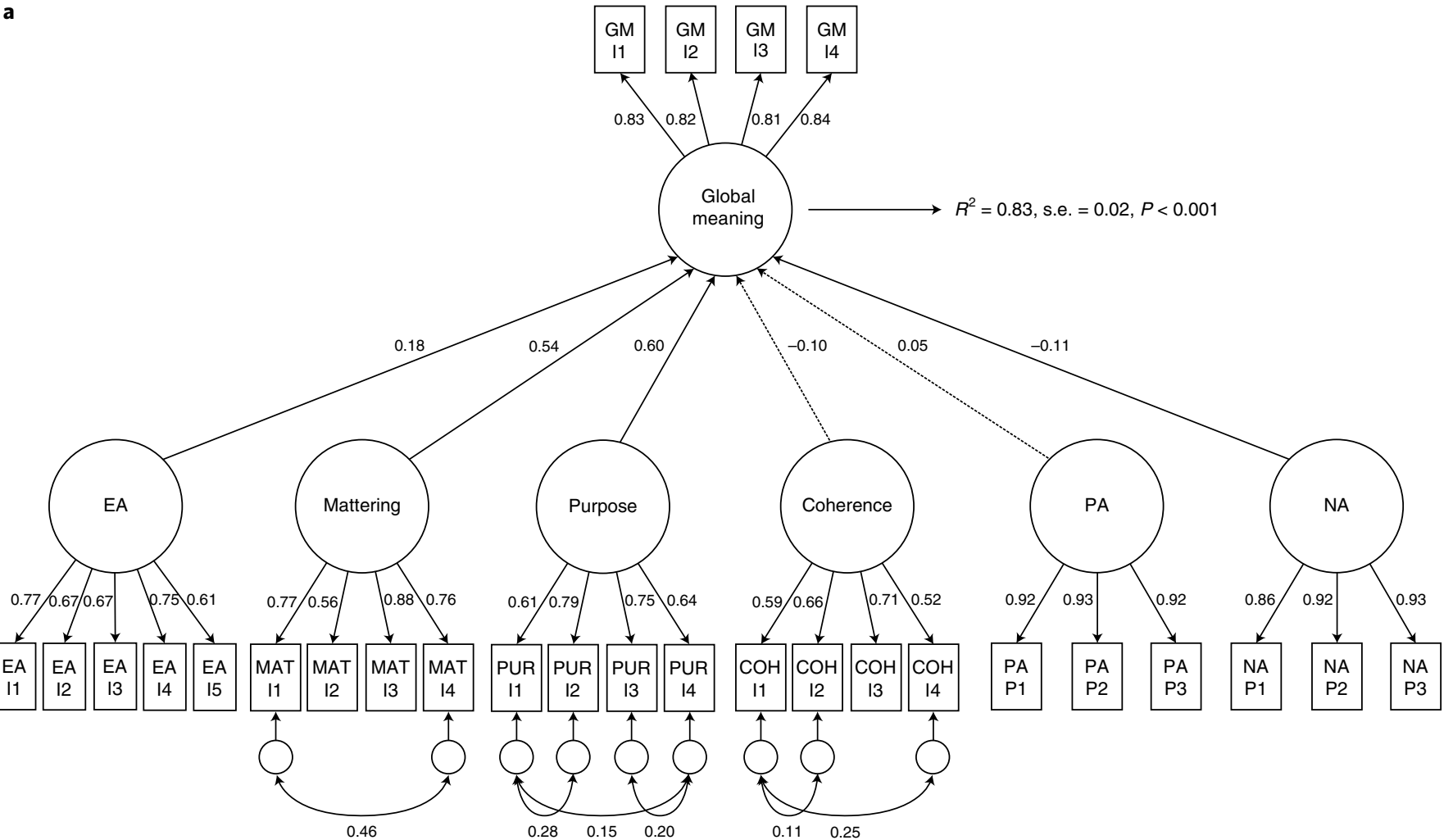

b

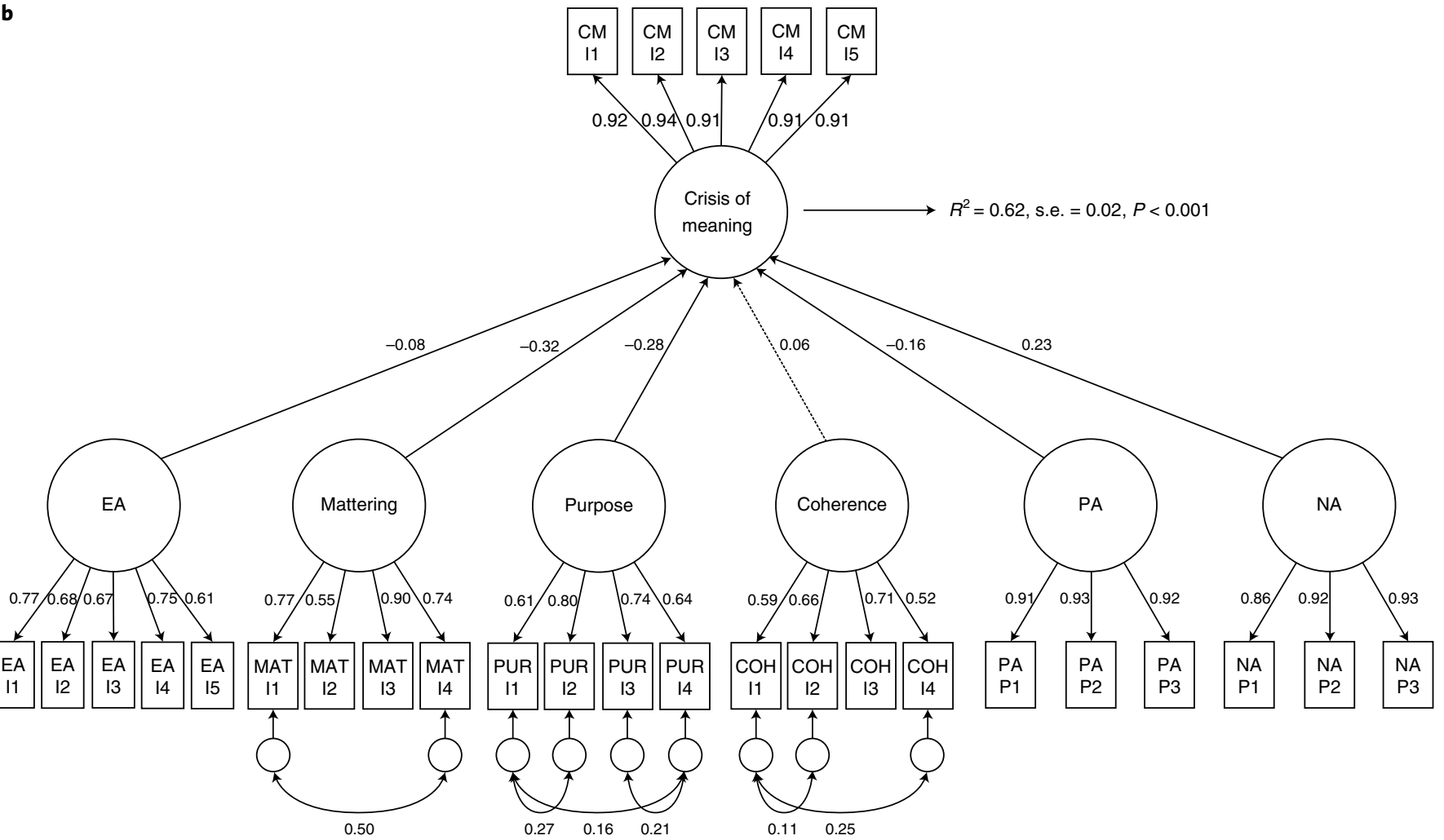

Fig. 1 | SEM depicting the contributors to meaning in study $\mathbf{2}$ with sample A. a, Global meaning in life as a dependent variable. $\mathbf{b}$, Crisis of meaning as a dependent variable. Estimates are standardized values. I's in observed variables denote individual items. P's in observed variables denote item parcels. All factor loadings and residual covariances are statistically significant at $P<0.001$. GM, general meaning; EA, experiential appreciation; MAT, mattering; PUR, purpose; $\mathrm{COH}$, coherence; $\mathrm{CM}$, crisis of meaning. 
$\mathbf{a}$
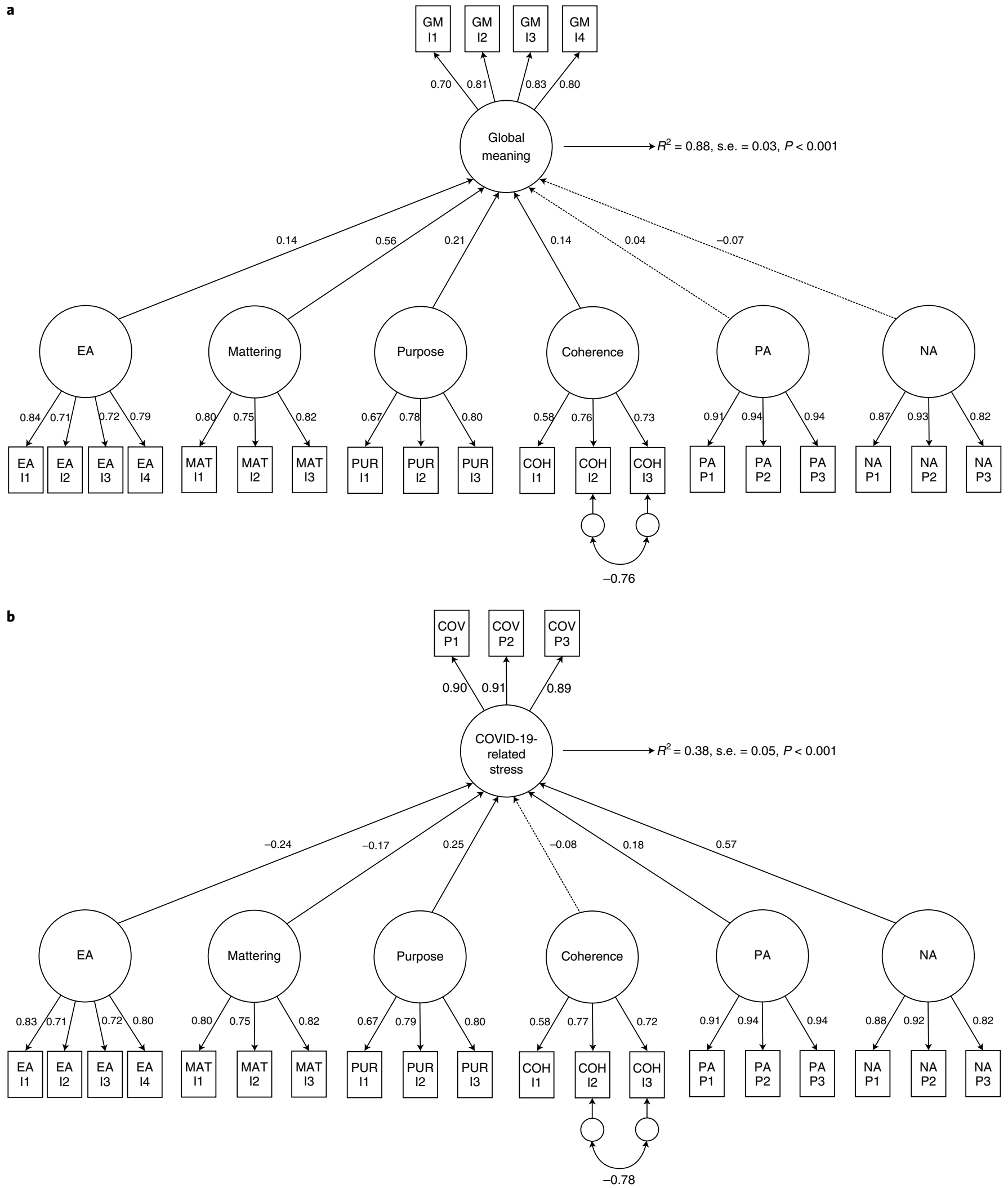

Fig. 2 | SEM depicting the contributors to meaning in study 2 with sample B. a, Global meaning in life as a dependent variable. b, COVID-19-related stress as a dependent variable. Estimates are standardized values. I's in observed variables denote individual items. P's in observed variables denote item parcels. All factor loadings and residual covariances are statistically significant at $P<0.001$. GM, general meaning; EA, experiential appreciation; MAT, mattering; PUR, purpose; $\mathrm{COH}$, coherence; CM, crisis of meaning; COV, COVID-19-related stress. 
Table 2 | Regression coefficients of event-related EA, tripartite meaning and mood on event-related global meaning in life in study 4

\begin{tabular}{|c|c|c|c|c|c|c|c|c|c|c|}
\hline \multirow[b]{2}{*}{ Predictor } & \multicolumn{5}{|c|}{ Model 1} & \multicolumn{5}{|c|}{ Model 2} \\
\hline & B & s.e. & $P$ & $95 \% \mathrm{Cl}$ & $\beta$ & B & s.e. & $P$ & $95 \% \mathrm{Cl}$ & $\beta$ \\
\hline Intercept & 1.25 & 0.27 & $<0.001$ & 0.72 to 1.78 & & 1.38 & 0.36 & $<0.001$ & 0.67 to 2.10 & \\
\hline Mattering & 0.24 & 0.04 & $<0.001$ & 0.16 to 0.32 & 0.29 & 0.24 & 0.04 & $<0.001$ & 0.16 to 0.33 & 0.30 \\
\hline Purpose & 0.14 & 0.06 & 0.014 & 0.03 to 0.26 & 0.14 & 0.12 & 0.06 & 0.045 & 0.003 to 0.23 & 0.11 \\
\hline NA & & & & & & -0.05 & 0.08 & 0.469 & -0.20 to 0.09 & -0.04 \\
\hline$R^{2}$ & 0.50 & & & & & 0.52 & & & & \\
\hline
\end{tabular}

means. The averages of these within-person correlations are presented in Extended Data Fig. 4.

Next, we conducted a multi-level model to examine whether EA uniquely predicted MIL over and above mattering, purpose and coherence. Due to the small number of level 1 units, it was not possible to treat all slopes as random. As such, we included a random slope for EA and fixed slopes for the other indicators of meaning since EA is the primary focus of this paper. Following the recommendations of ref. ${ }^{35}$, we used the obtained $t$ and $d f$ to calculate the effect size correlation ${ }^{36}$.

As predicted, all four proposed indicators of meaning significantly predicted daily MIL. Of particular importance, daily EA predicted daily MIL $(B=0.09$, s.e. $0.03, t(214)=2.99, P=0.003,95 \%$ CI $0.03-0.15, r=0.20)$, and this remained significant if the random slope was removed $(P=0.001)$. We also found significant relationships of daily mattering $(B=0.19$, s.e. $0.04, t(377)=4.71, P<0.001,95 \% \mathrm{CI}$ $0.01-0.17, r=0.24)$, daily purpose $(B=0.16$, s.e. $0.04, t(377)=4.39$, $P<0.001,95 \%$ CI $0.03-0.15, r=0.22)$ and daily coherence $(B=0.14$, s.e. $0.03, t(377)=4.30, P<0.001,95 \%$ CI $0.08-0.23, r=0.22)$ with daily MIL. Given that we could not treat all slopes as random at once, we also conducted three alternative models that treated mattering, purpose or coherence as fixed (in turn) whilst all other slopes were estimated as random. The significance levels did not change for any of these alternative models (details available at https://osf.io/4yx9p/).

We also conducted a second multi-level model that included daily EA and current affect as predictors of daily MIL, to examine whether EA would account for significant variance in daily MIL over and above affect. In this model, both PA $(B=0.21$, s.e. $0.04, t(214)$ $=5.17, P<0.001,95 \%$ CI $0.13-0.29, r=0.33)$ and NA $(B=-0.22$, s.e. $0.05, t(214)=-4.10, P<0.001,95 \% \mathrm{CI}-0.32$ to $-0.12, r=0.27)$ were significant predictors of daily MIL, but, importantly, so was daily EA $(B=0.07$, s.e. $0.03, t(214)=2.31, P=0.022$, $95 \%$ CI $0.01-$ $0.13, r=0.27)$. This suggests that the relationship between daily EA and daily MIL cannot simply be explained by current affect.

Finally, we conducted a third model that included the three indicators and mood in the same model. It is important that this model includes six level 1 predictors. Because there are only three to four level 1 observations per participant, the results of this model should be interpreted with some caution. Nonetheless, daily EA was not significant in this model $(B=0.01$, s.e. $0.03, t(214)=0.31, P=0.754$, $r=0.02)$. PA was by far the strongest predictor in this model $(B=0.17$, s.e. $0.04, t(214)=4.25, P=0.022, r=0.28)$. This analysis, though imperfect, does suggest that the relationship between daily EA and daily meaning may not be as robust as the trait-level relationships observed in preceding studies.

Study 4. First, we conducted a repeated-measures analysis of variance to examine the level of EA reported in the meaningful experiences compared with the level of mattering, purpose and coherence in the experiences. The results revealed a significant overall difference $\left(F(1,289)=10.43, P=0.001, \eta_{\mathrm{p}}{ }^{2}=0.04\right)$. Bonferroni post hoc comparisons found that the meaningful experiences were rated significantly higher in EA $(M=5.71$, s.d. 1.23) compared with mattering $(M=3.10$, s.d. $1.29 ; \Delta M=0.62$, s.e. $0.08, P<0.001$, $95 \%$ CI $0.41-0.82)$, purpose $(M=5.33$, s.d. $1.02 ; \Delta M=0.39$, s.e. $0.07, P<0.001,95 \%$ CI $0.21-0.56)$ and coherence $(M=5.43$, s.d. $1.04 ; \Delta M=0.29$, s.e. $0.06, P<0.001$, 95\% CI $0.13-0.45)$. Ratings of purpose and coherence were also significantly higher than ratings of mattering $(\Delta M=0.23$, s.e. $0.08, P=0.017,95 \%$ CI $0.03-0.43$; $\Delta M=0.33$, s.e. $0.07, P<0.001,95 \%$ CI $0.15-0.50$, respectively).

Extended Data Fig. 5 shows some selected examples of narratives that were rated high in EA and relatively low in the other indicators of MIL. This suggests that some experiences are personally meaningful due to their intrinsic value as opposed to how much they relate to a sense of mattering, purpose or coherence.

To test our main hypothesis that event-level EA would predict the perception that an event had contributed to MIL, event EA was entered into a regression analysis along with mattering, purpose and coherence predicting global meaning of the event. The model accounted for $50 \%$ of the variance in perceptions that the event had contributed to overall MIL $(F(4,284)=71.01$, $\left.P<0.001, \eta_{\mathrm{p}}{ }^{2}=0.50\right)$. Event EA, mattering, purpose and coherence were all significant predictors (for example, $B=0.23$, s.e. $0.05, t(284)=4.99, P<0.001,95 \%$ CI $0.14-0.32$ for EA; Table 2). To further demonstrate the robustness of this relationship, we ran a similar regression analysis with the addition of state PA and NA. This model accounted for $51.6 \%$ of the variance in event-related global MIL $\left(F(6,282)=50.02, P<0.001, \eta_{\mathrm{p}}{ }^{2}=0.52\right)$. EA, mattering, purpose and coherence remained significant, and PA was also a significant predictor (for example, $B=0.19$, s.e. $0.05, t(282)=$ $3.79, P<0.001,95 \%$ CI $0.09-0.28$ for EA). NA did not uniquely predict event-related global meaning (full results available at https://osf.io/4yx9p/).

Study 5. Bivariate correlations among the key variables are presented in Extended Data Fig. 6. Independent samples $t$ tests were conducted to test for an effect of the awe manipulation on global MIL, mattering and EA. As expected, there was no difference in MIL between conditions $\left(M_{\text {nature }}=6.13\right.$, s.d. 1.05 versus $M_{\text {comparison }}=6.03$, s.d. $1.09 ; t(348)=0.84, P=0.40,95 \%$ CI -0.13 to $0.32, d=0.09)$ and no difference in mattering between conditions $\left(M_{\text {nature }}=5.30\right.$, s.d. 1.38 versus $M_{\text {comparison }}=5.09$, s.d. $1.35 ; t(346)=1.43, P=0.154$, $95 \% \mathrm{CI}-0.08$ to $0.50, d=0.15)$. However, as predicted, there was a significant difference in EA between the nature $(M=5.92$, s.d. 0.78$)$ and comparison $(M=5.69$, s.d. 1.03$)$ conditions $(t(344)=2.34$, $P=0.02,95 \%$ CI $0.04-0.42, d=0.25$ ).

Next, we tested for EA as a mediator of the indirect effect of the awe induction on MIL whilst considering other related variables as 


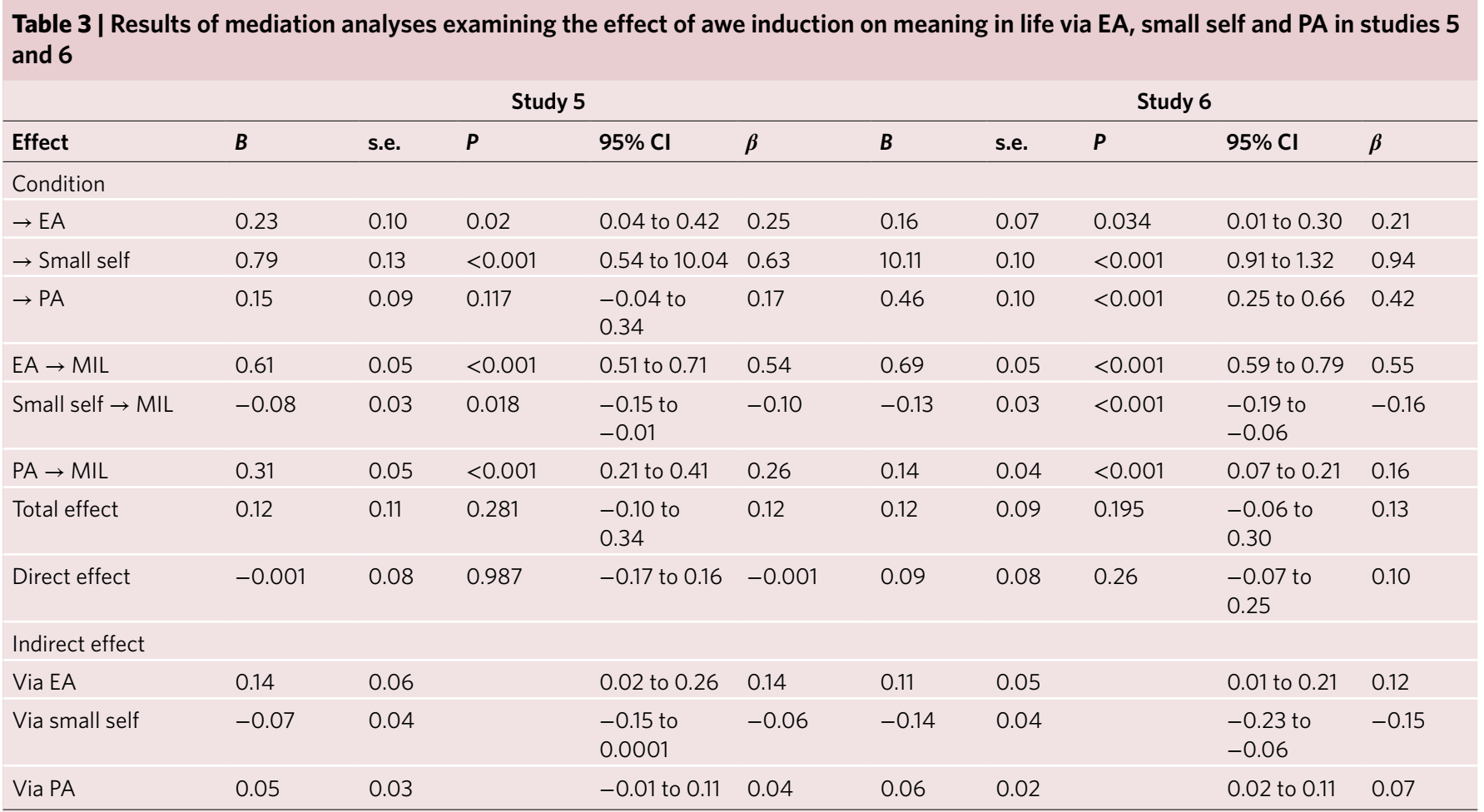

Note. Nature condition coded as 1. Comparison condition coded as 0 . Beta coefficients, standard errors and $95 \% \mathrm{Cls}$ for indirect effects are computed by the bootstrapping resampling method. Indirect effects are evaluated as statistically significant if the $95 \% \mathrm{Cl}$ does not include zero.

mediators. To this end, we performed a series of mediation analyses using the PROCESS macro for SPSS (model 4) ${ }^{37}$ with 10,000 iterations of bootstrapping resampling ${ }^{38}$. For the first model, awe induction was entered as the independent variable $(1=$ nature, $0=$ comparison), EA, small self and PA were entered as simultaneous mediators, and global MIL was entered as the dependent variable (Extended Data Fig. 7a). We found no significant total/direct effect of the awe induction on MIL (Table 3), which is consistent with previous research ${ }^{39}$. As predicted, the awe induction affected MIL indirectly via EA, but not via small-self feelings and PA. The indirect effect via small self was close to statistical significance (another test of the indirect effects with 10,000 bootstrapped resamples revealed its significant effect, $B=-0.07$, s.e. $0.04,95 \%$ CI -0.15 to -0.0003 ). However, if anything, the effect was negative.

A similar model was used to assess indirect effects of the awe induction on MIL via EA and mattering entered as simultaneous mediators. There was a significant indirect effect of condition on MIL through EA but not through mattering (Table 4).

Study 6. Bivariate correlations among the key variables are presented in Extended Data Fig. 8. A series of independent samples $t$ tests were conducted to test for an effect of the awe induction on global MIL, mattering, purpose, coherence and EA. As predicted, there was no difference in global MIL $\left(M_{\text {nature }}=6.10\right.$, s.d. 1.93 versus $M_{\text {comparison }}=5.98$, s.d. $0.91 ; t(420)=1.30, P=0.20,95 \%$ CI -0.06 to $0.29, d=0.13)$, mattering $\left(M_{\text {nature }}=5.49\right.$, s.d. 1.30 versus $M_{\text {comparison }}=5.32$, s.d. $1.27 ; t(420)=1.37, P=0.17,95 \% \mathrm{CI}$ -0.08 to $0.42, d=0.13)$, purpose $\left(M_{\text {nature }}=5.80\right.$, s.d. 1.06 versus $M_{\text {comparison }}=5.72$, s.d. $1.02 ; t(420)=0.74, P=0.46,95 \% \mathrm{CI}-0.12$ to $0.27, d=0.07)$ or coherence $\left(M_{\text {nature }}=5.05\right.$, s.d. 1.03 versus $M_{\text {comparison }}=4.94$, s.d. $1.05 ; t(420)=1.13, P=0.26,95 \% \mathrm{CI}-0.08$ to $0.31, d=0.11)$. However, as predicted, there was a significant difference in EA between nature $(M=5.92$, s.d. 0.73$)$ and comparison $(M=5.74$, s.d. 0.75$)$ conditions $(t(420)=2.49, P=0.01,95 \% \mathrm{CI}$ $0.04-0.32, d=0.24)$.
Next, we tested for EA as a mediator of the indirect effect of the awe induction on MIL whilst controlling for related variables using the PROCESS macro for SPSS (model 4) ${ }^{37}$ with 10,000 iterations of bootstrapping resampling ${ }^{38}$. As in study 5 , for the first model, awe induction was entered as the independent variable ( $1=$ nature, $0=$ comparison), EA, small self and PA were entered as simultaneous mediators, and MIL was entered as the dependent variable (Extended Data Fig. 7a). There again was no significant total/direct effect of the awe induction on MIL (Table 3). Consistently, the awe condition affected MIL indirectly via EA. Unlike study 5, we also found significant indirect effects via PA and small-self feelings, which influenced MIL in an opposite direction.

To replicate and extend the results of study 5, a similar model was used to assess indirect effect of the awe induction on MIL via EA, mattering, purpose and coherence entered as simultaneous mediators (Extended Data Fig. 7b). There was a significant indirect effect via EA. However, there were no such indirect effect through mattering, purpose or coherence (Table 4).

Study 7. Bivariate correlations among the key variables are presented in Extended Data Fig. 9. Next, we tested for EA as a mediator of the indirect effect of condition on MIL whilst controlling for related variables using the PROCESS macro for SPSS (model 4$)^{37}$ with 10,000 iterations of bootstrapping resampling ${ }^{38}$. For the first model, condition was entered as the independent variable $(1=\mathrm{EA}$, $0=$ control), EA, mattering, purpose and coherence were entered as simultaneous mediators, and MIL was entered as the dependent variable. We found a significant total effect of condition on MIL, but accounting for EA and the other three indicators of meaning caused the direct effect to be non-significant (Table 5). Consistent with our prediction, the mediational pathways through EA as well as all three indicators of meaning were significant. Together, this suggests that most of the between-condition variance in MIL can be explained by these variables. 
Table 4 | Results of mediation analyses examining the effect of awe induction on meaning in life via EA and tripartite components of meaning in studies 5 and 6

\begin{tabular}{|c|c|c|c|c|c|c|c|c|c|c|}
\hline \multirow[b]{2}{*}{ Effect } & \multicolumn{5}{|c|}{ Study 5} & \multicolumn{5}{|c|}{ Study 6} \\
\hline & B & s.e. & $P$ & $95 \% \mathrm{Cl}$ & $\beta$ & B & s.e. & $P$ & $95 \% \mathrm{Cl}$ & $\beta$ \\
\hline \multicolumn{11}{|l|}{ Condition } \\
\hline$\rightarrow$ Mattering & 0.21 & 0.15 & 0.143 & $\begin{array}{l}-0.07 \text { to } \\
0.50\end{array}$ & 0.16 & 0.17 & 0.13 & 0.173 & $\begin{array}{l}-0.08 \text { to } \\
0.42\end{array}$ & 0.13 \\
\hline$\rightarrow$ Purpose & & & & & & 0.07 & 0.10 & 0.459 & -0.12 to 0.27 & 0.07 \\
\hline $\mathrm{EA} \rightarrow \mathrm{MIL}$ & 0.46 & 0.05 & $<0.001$ & 0.37 to 0.56 & 0.41 & 0.29 & 0.04 & $<0.001$ & 0.21 to 0.37 & 0.23 \\
\hline Mattering $\rightarrow$ MIL & -0.37 & 0.03 & $<0.001$ & 0.31 to 0.43 & 0.48 & 0.36 & 0.02 & $<0.001$ & 0.32 to 0.41 & 0.51 \\
\hline Purpose $\rightarrow$ MIL & & & & & & 0.12 & 0.03 & $<0.001$ & 0.06 to 0.18 & 0.14 \\
\hline Coherence $\rightarrow$ MIL & & & & & & 0.13 & 0.03 & $<0.001$ & 0.07 to 0.19 & 0.15 \\
\hline \multicolumn{11}{|l|}{ Indirect effect } \\
\hline Via EA & 0.11 & 0.04 & & 0.02 to 0.19 & 0.10 & 0.05 & 0.02 & & 0.01 to 0.10 & 0.06 \\
\hline Via mattering & -0.08 & 0.05 & & -0.03 to 0.19 & 0.08 & 0.06 & 0.05 & & -0.03 to 0.16 & 0.07 \\
\hline Via purpose & & & & & & 0.01 & 0.01 & & $\begin{array}{l}-0.02 \text { to } \\
0.04\end{array}$ & 0.01 \\
\hline Via coherence & & & & & & 0.02 & 0.01 & & -0.01 to 0.05 & 0.02 \\
\hline
\end{tabular}

Note. Nature condition coded as 1. Comparison condition coded as 0 . Beta coefficients, standard errors and $95 \%$ Cls for indirect effects are computed by the bootstrapping resampling method. Indirect effects are evaluated as statistically significant if $95 \% \mathrm{Cl}$ does not include zero.

The second mediation model was structured identically, but with the inclusion of PA and vividness as additional mediators (Table 5). PA was a significant mediator of the relationship, whilst vividness was not. Importantly, even accounting for PA and event vividness, EA along with the tripartite indicators of meaning, except for coherence, were still significant mediators.

\section{Discussion}

The purpose of the current studies was to examine the idea that EA represents a key indicator of the experience of MIL that has previously been overlooked in the MIL literature. The results of study 1 demonstrated that coping with the COVID-19 pandemic by appreciating life uniquely influenced judgements of MIL. Study 2 more directly showed that EA uniquely predicted global judgements of MIL. Importantly these studies also demonstrated that EA was related to, but not redundant with, other key indicators of MIL. Study 3 found that daily reports of appreciating an event similarly predicted daily global MIL. Study 4 further showed that appreciating a specific experience was associated with the belief that the experience helped make life meaningful. In studies 5 and 6 , we successfully manipulated EA and found an indirect effect of our manipulation on MIL via EA. Finally, study 7 revealed that, after reflecting on experiences high in EA (versus more ordinary experiences), people reported higher levels of event-specific MIL. Importantly, across all studies, we demonstrated that EA was related to MIL over and above the contribution of mattering, purpose and coherence. Taken together, the results of the current work provide strong evidence that EA is an important proximal cue used to judge the meaningfulness of one's life.

Given that our work was inspired by the tripartite model of MIL, it is worth considering how the current findings might inform that model. Following recent proposals for a hierarchical model of well-being ${ }^{40}$, we tend to view meaning as a single, higher-order concept of general MIL, which can then be divided into a number of theoretically separate lower-level facets of meaning in a similar way that intelligence literature includes both ' $\mathrm{g}$ ' as a general construct at the top, and more domain-specific dimensions of intelligence below it. Understanding MIL as having a general higher-level construct, and a few key lower-level facets such as coherence, purpose and mattering, can address some of the definitional ambiguity of subjective MIL judgements and encourages the study of each facet of meaning separately. Whilst our studies continue to support the idea that mattering, purpose and coherence are unique cues for the experience of MIL, and thus potential key facets of the general sense of meaning, the current findings suggest that the structure of MIL may be broader than previous research suggests ${ }^{3}$. Our data hint at the possibility that a more consummate model of MIL may need to take into account the extent to which individuals' value and appreciate their daily experiences. Of course, we should note that neither our data, nor previous studies, have directly examined the structure of MIL.

As noted in the preceding paragraphs, one unanswered question lies in the exact relationship between EA and MIL. We have argued that EA is a highly utilized cue in the MIL judgement process and potentially one of the key lower-level components of overall sense of MIL. We tested this assertion by showing that EA predicts global MIL over other proposed facets of meaning. This approach follows what others have done when examining the tripartite model of meaning ${ }^{41}$, and such evidence has been used to make claims such as "meaning is about mattering" ${ }^{3}$. Instead of claiming that meaning is "about" EA, we treat our evidence as giving support for seeing EA as one of the key indicators of a general sense of MIL. Of course, 
Table 5 | Results of mediation analyses examining the effect of EA induction on meaning in life via multiple mediators in study 7

\begin{tabular}{|c|c|c|c|c|c|c|c|c|c|c|}
\hline \multirow[b]{2}{*}{ Effect } & \multirow[b]{2}{*}{ B } & \multicolumn{4}{|c|}{ Model 1} & \multicolumn{5}{|c|}{ Model 2} \\
\hline & & s.e. & $P$ & $95 \% \mathrm{Cl}$ & $\beta$ & $B$ & s.e. & $P$ & $95 \% \mathrm{Cl}$ & $\beta$ \\
\hline \multicolumn{11}{|l|}{ Condition } \\
\hline$\rightarrow$ Mattering & 1.15 & 0.13 & $<0.001$ & 0.90 to 1.40 & 0.76 & 1.15 & 0.13 & $<0.001$ & 0.90 to 1.40 & 0.76 \\
\hline$\rightarrow$ Purpose & 0.60 & 0.09 & $<0.001$ & 0.43 to 0.78 & 0.59 & 0.61 & 0.09 & $<0.001$ & 0.43 to 0.78 & 0.59 \\
\hline$\rightarrow$ Vividness & & & & & & 0.09 & 0.06 & 0.121 & -0.02 to 0.21 & 0.14 \\
\hline $\mathrm{EA} \rightarrow \mathrm{MIL}$ & 0.22 & 0.04 & $<0.001$ & 0.15 to 0.30 & 0.27 & 0.19 & 0.04 & $<0.001$ & 0.12 to 0.27 & 0.24 \\
\hline Mattering $\rightarrow$ MIL & 0.22 & 0.03 & $<0.001$ & 0.16 to 0.28 & 0.29 & 0.21 & 0.03 & $<0.001$ & 0.15 to 0.27 & 0.29 \\
\hline Purpose $\rightarrow$ MIL & 0.20 & 0.05 & $<0.001$ & 0.10 to 0.30 & 0.18 & 0.18 & 0.05 & $<0.001$ & 0.08 to 0.27 & 0.16 \\
\hline Direct effect & 0.06 & 0.08 & 0.487 & -0.11 to 0.22 & 0.05 & 0.09 & 0.08 & 0.258 & -0.07 to 0.25 & 0.08 \\
\hline \multicolumn{11}{|l|}{ Indirect effect } \\
\hline Via EA & 0.31 & 0.07 & & 0.19 to 0.44 & 0.28 & 0.27 & 0.06 & & 0.15 to 0.40 & 0.24 \\
\hline Via mattering & 0.25 & 0.05 & & 0.16 to 0.35 & 0.22 & 0.24 & 0.05 & & 0.16 to 0.34 & 0.22 \\
\hline Via purpose & 0.12 & 0.04 & & 0.05 to 0.20 & 0.11 & 0.11 & 0.04 & & 0.04 to 0.19 & 0.09 \\
\hline Via coherence & 0.08 & 0.04 & & 0.01 to 0.16 & 0.07 & 0.06 & 0.04 & & -0.01 to 0.13 & 0.05 \\
\hline Via PA & & & & & & 0.03 & 0.02 & & 0.005 to 0.07 & 0.03 \\
\hline Via vividness & & & & & & 0.02 & 0.01 & & -0.004 to 0.05 & 0.02 \\
\hline
\end{tabular}

Note. EA condition coded as 1. Control condition coded as 0 . Beta coefficients, standard errors and $95 \% \mathrm{Cls}$ for indirect effects are computed by the bootstrapping resampling method. Indirect effects are evaluated as statistically significant if $95 \% \mathrm{Cl}$ does not include zero.

as stated above, this type of empirical evidence alone cannot determine whether EA (or mattering, purpose or coherence) is a facet of meaning. Rather, these results only illustrate that EA is associated with meaning over and above mattering, purpose and coherence. Determining the key facets of meaning requires further theoretical and empirical work.

Important limitations should be considered when interpreting the current findings. First, whilst our measure of EA demonstrated high construct and incremental validity, as understanding of EA evolves, it is likely that the scale itself will need refinement. It is also noteworthy that the effects of our experimental manipulations were relatively weak. Finally, the majority of participants in the current studies were from the United States. Although there is little reason to believe EA would be less important to judgements of MIL in other cultures as shown in our Chinese sample in study 2, the generalizability of the importance of valuing experiences on judgements of meaning needs empirical backing.

Although many universal and idiosyncratic sources bear on the subjective experience of MIL, the core of this experience is influenced by several primary indicators of a higher-level general sense of MIL. A life that once seemed inherently full of meaning can become confusing and senseless when traumatic events disrupt one's typical way of perceiving it. Moreover, the internalization of valued goals or the belief that one's actions are not, ultimately, all for naught, can subsequently restore faith that one's life is meaningful. The current studies demonstrate that, like coherence purpose, and mattering, the appreciation of life events is inextricably tied to the perception of personal meaning. Consistent with Frankl's eloquent observation, our findings suggest that simply appreciating one's experiences can foster a rich sense of meaning and perhaps shore up confidence that life has been and will be worth living.

\section{Methods}

All studies reported in this work were approved by the Institutional Review Board at Texas A\&M University and comply with all relevant ethical regulations. Participants provided informed consent.

Study 1. Participants. We analysed a recent international dataset that assessed the relationship between various coping strategies and health and well-being during the initial phases of the COVID-19 pandemic. A total of 11,227 people from 30 countries completed the study. Participants were from all six major world regions (that is, geolocations) according to the United Nations geoscheme, including Africa $(n=973)$, Asia $(n=2,945)$, Europe $(n=5,394)$, Latin America and the Caribbean $(n=1,206)$, North America $(n=613)$ and Oceania $(n=96)$. The mean age of the sample was 35.36 years (s.d. 13.26 years; range $18-85$ years). Approximately $70 \%$ of the participants identified as female.

Materials. Life Appreciation, Mattering, Purpose and Coherence. As an initial test of our hypothesis, we examined whether coping strategies associated with each proposed indictor of meaning would predict global reports of MIL. Participants were asked to rate their agreement with specific statements related to the strategies they were using to cope with the COVID-19 pandemic. As a proxy for EA, participants rated two items assessing life appreciation, including 'I appreciate my life as it is right now regardless of the circumstances' and 'I am grateful for my life as it is' $(M=5.40$, s.d. $1.58, r=0.62)$. As a proxy for mattering, participants completed two items associated with social mattering ${ }^{42}$, including 'I'm doing what is good for our society' and ' $I$ help others during this time' $(M=5.31$, s.d. $1.37, r=0.43$ ). To assess purpose, participants rated their goal pursuit behaviour using a single item ('I do something productive every day'; $M=5.18$, s.d. 1.79). Each of these items was assessed on a seven-point scale (from 1 for 'I do not agree at all' to 7 for 'I completely agree'). To assess coherence, or the extent to which participants have made sense of the event, we aggregated four items from the positive reappraisal and acceptance subscales of the brief Coping Orientation to 
Problems Experienced inventory $y^{43}$ as a proxy for coping strategies aimed at finding coherence. Example items included 'I've been looking for something good in what is happening' and 'I've been accepting the reality of the fact that it has happened' $(M=2.76$, s.d. $0.78, \alpha=0.74)$. These items were assessed on a four-point scale (from 1 for 'I haven't been doing this at all' to 4 for 'I've been doing this a lot').

MIL. To assess global MIL, participants completed the three-item MIL subscale of the Positive Emotion, Engagement, Relationship, Meaning and Accomplishment profiler $^{44}$. Items included 'In general, to what extent do you lead a purposeful and meaningful life?', 'In general, to what extent do you feel that what you do in your life is valuable and worthwhile?', and 'To what extent do you generally feel you have a sense of direction in your life?'. Participants rated these items on a seven-point scale (from 0 for 'never' to 6 for 'always'; $M=4.43$, s.d. $1.27, \alpha=0.86$ ).

Study 2. Participants. Participants in study 2 were drawn from two separate samples. Sample A included 1,493 undergraduate students at Texas A\&M University (1,013 female, 466 male, 3 other, 11 did not report) in the United States. Sample A was composed of three separate samples of participants who completed a 30-min survey during the academic school year. Each of these three surveys included measures related to MIL. Given that the results for the main analyses remain consistent when each sample is analysed separately, we merged the samples for analyses in the current manuscript. Sample B included 297 participants from a Nanjing University ( 215 female, 82 male). All students participated in the study for partial completion of course requirements for a psychology course. For sample A, mean age was 19.65 years (s.d. 1.44 years). The sample was primarily White (79.2\%), and non-Hispanic (74.9\%). For sample B, mean age was 21.51 years (s.d. 2.31 years). The sample was composed exclusively of Chinese nationals. We excluded 40 participants of sample A as they indicated they 'just clicked through the study or otherwise did not take part seriously' and their 'data should be removed' on a forced-choice question assessed at the end of the survey ${ }^{45}$. Thus, we entered the responses of 1,453 participants in the analyses. This seriousness check item was not included in the survey for sample B.

Materials and procedure. All participants completed the survey online at their convenience. All participants were prompted to respond to all measures. Measures were chosen to establish convergent and discriminant validity for the proposed measure of EA. To assess the relationship between EA and other theoretical perspectives on MIL, both multi-dimensional and global measures of MIL were included. Subsequent measures in the study served to assess constructs theoretically linked with EA (for example, mindfulness, savouring and connectedness to nature) and are available at https://osf.io/4yx9p/. Unless otherwise noted, participants were instructed to rate their agreement with each statement on a Likert scale from 1 ('strongly disagree') to 7 ('strongly agree'). For sample B, all study measures were initially translated into Chinese by H.Z. and then back-translated into English by an independent translator who is fluent in both English and Chinese. This procedure was repeated until the Chinese versions of measures were equivalent to the original English versions of measures. Participants of sample B completed the finalized Chinese versions of measures.

EA. Twelve items were initially generated to assess the proposed theoretical construct $\overline{\text { of EA}}$. We conducted an exploratory factor analysis on a subset of participants in sample A $(n=469)$ to identify items that best reflected the construct of EA (see results below), reducing the scale to five items. Participants rated their agreement on these items with statements such as 'I have a great appreciation for the beauty of life', 'I appreciate the little things in life', 'I appreciate a wide variety of experiences' and 'I take great interest in my daily activities' ( $M=5.53$, s.d. $0.95, \alpha=0.91$ for sample A; $M=5.46$, s.d. $0.91, \alpha=0.85$ for sample B; see Extended Data Fig. 2 for all items).

Multi-dimensional measures of MIL. Mattering, purpose and coherence were assessed with the tripartite MIL scale by Costin and Vignoles ${ }^{3}$. These items include the three four-item subscales for mattering $(M=4.86$, s.d. 1.43, $\alpha=0.82$ for sample A; $M=5.06$, s.d. $1.36, \alpha=0.83$ for sample B), purpose $(M=5.31$, s.d. $1.20, \alpha=0.74$ for sample A; $M=4.77$, s.d. $1.17, \alpha=0.78$ for sample B) and coherence $(M=4.84$, s.d. $1.43, \alpha=0.84$ for sample A; $M=4.95$, s.d. $0.98, \alpha=0.62$ for sample $B$; see Table 1 for all items).

Global meaning. Global judgement about MIL was assessed using two separate scales. First, four items from Costin and Vignoles ${ }^{3}$ asked participants to rate the meaningfulness (or lack thereof) of their life as a whole $(M=5.66$, s.d. 1.24 , $\alpha=0.81$ for sample A; $M=5.42$, s.d. $1.10, \alpha=0.87$ for sample B) using face-valid meaning items (for example, 'My entire existence is full of meaning' and 'My life is meaningless'). Second, to assess the extent to which participants felt distress over a lack of meaning, the five-item crisis subscale $(M=2.09$, s.d. $1.37, \alpha=0.96$ for sample A) of the Sources of Meaning and Meaning in Life Questionnaire ${ }^{46}$ was included in sample A's questionnaire only (for example, 'I suffer from the fact that I don't see any point in life').

Post-traumatic stress symptoms. Sample B completed their survey following the onset of the COVID-19 pandemic, giving us a unique opportunity to assess the contribution of EA to psychological stress related to the pandemic. Although this inquiry was exploratory in nature, a long line of research and theory speaks to the importance of finding meaning during difficult times ${ }^{47}$. This analysis, therefore, gave us the opportunity to shed light on the specific indicators of meaning that help mitigate suffering during this unprecedented time, as well as whether EA would predict less stress over and above the other indicators of meaning. Participants completed the 17-item Post-traumatic Stress Disorder Checklist-Civilian Version ${ }^{48}$. We adapted this measure to assess psychological distress specifically related to the COVID-19 pandemic. Specifically, participants were given a list of possible problems and complaints in response to the COVID19 pandemic (for example, 'Loss of interest in things that you used to enjoy', 'Feeling distant or cut off from other people' and 'Trouble falling or staying asleep') Participants rated their responses on a five-point scale (from 1 for 'not at all' to 5 for 'extremely'). Their responses to the items were then summed, which resulted in a possible range of scores from 17 to $85(M=33.27$, s.d. 12.30).

Mood. We also assessed mood as a covariate, given its relation to $\mathrm{MIL}^{30}$. Participants were asked to indicate how much they felt each of 12 positive emotions (for example, calm, happy; $M=3.22$, s.d. $0.84, \alpha=0.94$ for sample A; $M=3.12$, s.d. $0.80, \alpha=0.94$ for sample B) and 13 negative emotions (for example, sad, stressed; $M=2.57$, s.d. $0.81, \alpha=0.91$ for sample A; $M=2.53$, s.d. $0.68, \alpha=0.87$ for sample B) in general, which were adapted from the Positive and Negative Affect Schedule ${ }^{49}$. They rated each emotion on a scale from 1 ('very slightly or not at all') to 5 ('extremely')

Exploratory and confirmatory factor analyses for sample A. We conducted an exploratory factor analysis on the first U.S. sample $(n=469)$ with the intent of identifying items that effectively assessed the construct of EA. The collection of items with factor loadings based on the exploratory factor analysis is shown in Extended Data Fig. 2. To explore the factor structure, we subjected all items in the EA scale to a maximum likelihood extraction with a Promax rotation, as per the recommendations of Costello and Osborne ${ }^{50}$. In our exploratory factor analysis, we considered an item to be a strong indicator with the construct if it loaded onto the factor with a loading greater than 0.50 .

In reducing our scale, we decided to exclude two items that assessed valuing one's existence, more generally (for example, 'My existence is valuable to me'), as well as another two items that explicitly assessed perceptions of finding happiness or pleasure in one's experiences (for example, 'Merely being alive gives me pleasure'). These exclusions were based on how the conceptualization of our construct evolved, potential overlap between the first two items and the mattering construct and overlap between the last two items and PA. We then chose five items that demonstrated the highest loadings in an effort to keep the length of the scale consistent with current measures of MIL ${ }^{5,6}$. These items loaded from 0.75 to 0.83 on a single factor and had high reliability ( $\alpha=0.83$; Extended Data Fig. 2).

To ensure that EA is a distinct factor from the other three indicators of meaning, we conducted a CFA, which included the five items of EA, mattering, purpose and coherence, with the rest of sample A $(n=986)$ using Mplus (version $8.0)^{33}$. CFAs were estimated using full maximum likelihood. The model fit is evaluated as good or acceptable if an RMSEA value is close to 0.08 or below ${ }^{51}$, a CFI value is greater than 0.90 (ref. ${ }^{52}$ ) and an SRMR value is close to 0.08 or below $^{53}$. The initial CFA revealed a less acceptable model fit to the data $\left(\chi^{2}(113)\right.$ $=941.30, P<0.001$, RMSEA 0.086 (90\% CI 0.081-0.091), CFI 0.893, SRMR 0.056). To improve the model fit, we probed whether (a) any item of EA had more than two significant cross-loadings with modification indices larger than 10 and (b) there were any items within each factor whose modification indices of residual covariance were larger than 10 and association theoretically makes sense (for example, 'Whether my life ever existed matters, even in the grand scheme of the universe' and 'Given the vastness of the universe, my life does not matter' for mattering). We found several cases of residual covariance (Fig. 1a), and reran another CFA with the residual covariances included. The final CFA yielded an acceptable model fit $\left(\chi^{2}(107)=625.80, P<0.001\right.$, RMSEA $0.07(90 \% \mathrm{CI}$ 0.065-0.075), CFI 0.933, SRMR 0.051). Thus, we relied on this factor structure in all subsequent analyses for sample A (see Table 1 for factor loadings; details for the CFA are available at https://osf.io/4yx9p/).

Measurement invariance and CFA for sample B. Before analysing the data of sample $B$, we evaluated measurement invariance of the primary scales to ensure measurement and structural invariance across our U.S. and Chinese samples. To this end, we performed a series of multi-group CFA with Mplus (version 8.0) ${ }^{33}$ to examine configural and metric invariances of the scales across samples by using the second subset of sample A $(n=986)$ and sample B $(n=297)$. In the configural invariance model, only the general factor structure was evaluated to be equivalent across samples. The factor means were fixed at 0 for model identification within each group ${ }^{54}$. The configural invariance test was evaluated based on the model fit indices (for example, CFI greater than 0.90). In the metric invariance model, we examined the equality of the item factor loadings across samples by imposing the constraint that the factor loadings are invariant across samples. Given that the metric invariance model was nested within the configural invariance model, a $\chi^{2}$ difference test was used to evaluate the metric invariance test. If the $\chi^{2}$ difference 
was not statistically significant (that is, $P>0.05$ ), the metric invariance model did not significantly worsen the model fit of the configural invariance model, suggesting that the metric invariance of the scales across samples is supported.

First, we specified the configural invariance model by including the five items of EA and the four items of each of the three MIL components (for example, mattering). Based on what we found in the CFA for sample A, we also included the residual covariances in the model. This configural invariance model revealed an acceptable model fit to the data $\left(\chi^{2}(214)=875.85, P<0.001\right.$, RMSEA 0.069 (90\% CI 0.065-0.074), CFI 0.934, SRMR 0.052), suggesting that the configural invariance of the scales across samples can be assumed. We then conducted the metric invariance model by specifying that the item factor loadings across groups are equivalent, and found that it significantly differed from the configural invariance model $\left(\Delta \chi^{2}(13)=95.76, P<0.001\right)$. Although this was the evidence against measurement invariance, we examined partial metric invariance as recommended in the previous research ${ }^{54}$. Specifically, we first rank-ordered the absolute magnitude of the unstandardized factor loadings of the items within each factor. We then identified the items that exhibited large discrepancies in their factor loadings between samples, which revealed that there was one item for each factor that seems to have different factor loadings between two samples ('I tend to find myself deeply engaged in conversations with other people' for EA, 'Whether my life ever existed matters even in the grand scheme of the universe' for mattering, 'I don't have compelling life goals that keep me going' for purpose and 'Looking at my life as a whole, things seem clear to me' for coherence). We conducted the partial metric invariance model by freely estimating the factor loadings of these items in sample B and found that it did not statistically differ from the configural invariance model $\left(\Delta \chi^{2}(9)=15.37, P=0.081\right)$, suggesting that there is evidence for partial metric invariance. Hence, we retained all the items excluding those with the considerably different factor loadings for analysing the data of sample B.

Before the data analysis, we conducted a CFA to finalize the factor structure of the scales for sample B. In this CFA, we included the four items of EA and the three items for each of the MIL components. The model did not fit the data well $\left(\chi^{2}(59)\right.$ $=219.21, P<0.001$, RMSEA 0.096 (90\% CI 0.082-0.109), CFI 0.901, SRMR 0.062). As done in the CFA for sample A, we probed whether any residual covariance of observed variables within factors should be specified in the CFA based on the modification indices and modified the model by including a residual covariance between two items of the coherence factor (that is, 'I can make sense of the things that happen in my life' and 'My life feels like a sequence of unconnected events'). This model fit the data better $\left(\chi^{2}(58)=183.68, P<0.001\right.$, RMSEA $0.085(90 \%$ CI 0.072-0.099), CFI 0.922, SRMR 0.055), and thus we used this factor structure for all the subsequent analyses for sample B (see Table 1 for factor loadings; details for the CFA are available at https://osf.io/4yx9p/).

Study 3. Participants. Participants were 246 undergraduate students at Texas A\&M University (180 female, 44 male, 22 did not complete demographics). They participated in the study for partial completion of course requirements for a psychology course. Ages in the sample ranged from 18 to 27 years $(M=18.73$ years, s.d. 1.16 years). The sample was mainly White (76.7\%), and non-Hispanic (79.9\%). We excluded participants who completed less than three daily responses $(n=31)$ as well as seven daily responses that participants indicated should be removed and eight daily responses where participants failed to start the survey. Out of 984 possible daily responses (one per participant per day), our remaining sample was 810 daily responses ( $83.6 \%$ of possible responses).

Materials and procedure. Participants completed four daily diary surveys. To minimize differences between waves, these surveys were collected from Monday to Thursday during two non-holiday weeks in the Fall semester. In all analyses, we tested for differences between waves and collapsed across waves if no significant differences were found. In addition, for descriptive statistics, we collapsed across days.

EA. To assess EA, we used five items adapted from our original scale to focus on

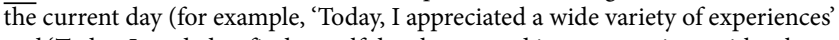
and 'Today, I tended to find myself deeply engaged in conversations with other people'). Participants evaluated the EA items on the same seven-point scale $(M=4.84$, s.d. $1.18, \alpha=0.85)$. These items were randomly ordered in a 17 -item composite questionnaire that also included mattering, purpose and coherence.

Mattering, purpose and coherence. Participants completed the three scales assessing mattering, purpose and coherence adapted from Costin and Vignoles ${ }^{2}$. All items were adapted to focus on the participant's experience that day in mattering ( $M=5.05$, s.d. 1.11, $\alpha=0.66$; for example, 'Today, I feel whether my life ever existed matters, even in the grand scheme of the universe'), purpose $(M=5.42$, s.d. 1.09 , $\alpha=0.80$; for example, 'Today, I have a good sense of what I am trying to accomplish in life') and coherence ( $M=4.89$, s.d. 1.17, $\alpha=0.80$; for example, 'Today, looking at my life as a whole, things seem clear to me'). These items were included in the 17-item composite questionnaire alongside the EA items, with the questions presented randomly.

Current MIL. MIL was assessed with four items adapted from Costin and Vignoles $^{2}$. It was assessed as a state measure following the 17 -item composite questionnaire, specifying the timescale as 'right now' $(M=5.65$, s.d. $1.15, \alpha=0.93$; for example, 'Right now, my life as a whole has meaning').

Mood. Finally, participants indicated their current mood using an abbreviated Positive and Negative Affect Schedule ${ }^{49}$ of eight items: four PA $(M=3.15$, s.d. 1.08 , $\alpha=0.92$; for example, 'Currently, I feel happy') and four NA states $(M=1.62$, s.d. 0.73, $\alpha=0.76$; for example, 'Currently, I feel unpleasant') on a five-point scale (from 1 for 'very slightly or not at all' to 5 for 'extremely').

Study 4. Participants. Participants included 315 undergraduate students at Texas A\&M University who participated in the study for partial completion of course requirements for an introductory psychology course. Sixteen of these participants were removed from analysis based on our seriousness check question. The final sample included 299 students (169 female, 120 male, 1 other, 9 did not report) aged 18 to 27 years $(M=19.19$ years, s.d. 1.25 years). The sample was primarily White (79.6\%), and non-Hispanic (87\%).

Materials and procedure. Data for this study were collected via survey programmed in Qualtrics. A portion of participants (49.2\%) came into the laboratory to complete the survey in private cubicles. The rest of the participants $(52.8 \%)$ took the survey online at their convenience.

Event details. Participants were asked to identify the most meaningful event that had taken place in the last week. They were then asked to describe the event and explain why it was meaningful. Participants were reminded at this point in the survey that they should keep this particular event in mind when answering questions.

Event-specific MIL. Participants rated the contribution of the event to their global sense of MIL $(M=5.56$, s.d. 1.06, $\alpha=0.76)$ using four global meaning items adapted from Costin and Vignoles ${ }^{3}$ (for example, 'This event/experience made me feel as though my life as a whole had meaning') on a seven-point scale (from 1 for 'strongly disagree' to 7 for 'strongly agree'). This event-specific meaning approach is similar to that used by other scholars ${ }^{7,55-57}$.

Event tripartite meaning. Each of the four items assessing mattering, purpose and coherence of the event were adapted from Costin and Vignoles' tripartite meaning scale $^{3}$. All items were rated on a seven-point scale (from 1 for 'strongly disagree' to 7 for 'strongly agree'). Example items of event mattering $(M=5.10$, s.d. 1.29, $\alpha=0.79)$, purpose $(M=5.33$, s.d. $1.02, \alpha=0.49)$ and coherence $(M=5.43$, s.d. $1.04, \alpha=0.74)$ include 'Whether this event/experience ever happened matters even in the grand scheme of my life', 'This event/experience is consistent with what I am trying to accomplish in life,' 'I can make sense of this event/experience in the context of my life', respectively.

Event EA. Five items adapted from previous studies were used to assess event EA (for example, 'I felt great appreciation for the beauty of this event/experience'; $M=5.71$, s.d. $1.23, \alpha=0.88)$.

State mood. Participants also rated the extent to which they felt four positive (for example, pleasant, happy; $M=3.43$, s.d. 1.12, $\alpha=0.93$ ) and four negative (for example, sad, angry; $M=1.47$, s.d. $0.72, \alpha=0.81$ ) emotions currently on a scale from 1 ('very slightly or not at all') to 5 ('extremely').

Study 5. Participants. Participants were 351 undergraduate students at Texas A\&M University (236 female, 110 male, 3 other or gender nonconforming, 2 did not report) who participated in the study for partial completion of course requirements for an introductory psychology course. Ages in the sample ranged from 18 to 53 years $(M=19.31$ years, s.d. 2.08 years). However, $96 \%$ of the participants were aged $18-21$ years. The sample was primarily White (61.6\%), and non-Hispanic (79.5\%).

Materials and procedure. Ninety-three participants completed the survey on laboratory computers in private cubicles, whilst the rest of the sample completed the survey online at their convenience. The survey consisted of an awe manipulation followed by measures of EA, meaning and mood.

Awe induction. Participants were randomly assigned to either an awe induction $(n=176)$ or comparison condition $(n=175)$. Those in the awe condition watched the 2-min opening sequence of 'Planet Earth' featuring beautiful and vast scenes from nature accompanied by slowly building instrumental music (https://youtu.be/fRBFSkc4oyw). Similar montages of nature scenes from 'Planet Earth' used in previous research have produced reliable differences in reported awe from the control condition ${ }^{39,58}$. Participants in the comparison condition watched a 2-min instructional woodworking video featuring a man describing how to finish a wooden countertop (https://youtu.be/bnKu0xg243U), which has been used in previous awe research as a comparison condition ${ }^{58-60}$. This video was very neutral in nature, and contrary to the neutral stimuli used in the previous study, we did not believe it would increase EA for the vast majority of participants. 
EA and meaning. The same five items from previous studies were used to assess EA $(M=5.85$, s.d. $0.92, \alpha=0.87)$, and the same four items were used to assess mattering $(M=5.20$, s.d. $1.36, \alpha=0.87)$. Due to time constraints, we chose to only assess mattering given its robust relationship with $\mathrm{MIL}^{3}$ to explore the possibility that awe might actually detract from feelings of mattering. Global MIL was measured with the four-item scale from Costin and Vignoles ${ }^{3}(M=6.08$, s.d. 1.06 $\alpha=0.93$ )

Mood. To assess current mood, we again asked participants to indicate how

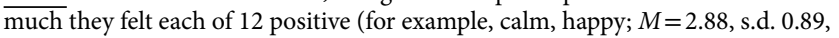
$\alpha=0.94$ ) and 13 negative emotions (for example, sad, stressed; $M=1.85$, s.d. 0.75 $\alpha=0.92$ ) right now on a five-point scale (from 1 for 'very slightly or not at all' to 5 for 'extremely') $)^{49}$

Emotions during the video. Participants also indicated the intensity of an awe emotion felt during the video, which was used to evaluate the awe induction $(M=3.79$, s.d. 2.30). Given the previous studies demonstrating that awe enhances happiness ${ }^{61}$, we also asked participants to indicate the intensity of happiness felt during the video $(M=3.58$, s.d. 2.07). These emotion ratings were made on a seven-point scale (from 1 for 'I did not feel this at all' to 7 for 'I felt this very intensely').

Small self. Finally, six items assessing the experience of small self (for example, 'I felt insignificant in the grand scheme of things'; $M=2.18$, s.d. $1.25, \alpha=0.87$ ) were presented in random order and rated on a seven-point scale (from 1 for 'I did not feel this at all' to 7 for ' $I$ felt this very intensely'). We assessed this scale given its negative relationship with $\mathrm{MIL}^{39}$, as well as for exploratory purposes due to its conceptual similarity to the inverse of the mattering construct.

Manipulation effectiveness. Consistent with previous research and predictions, participants reported greater awe in the nature $(M=5.46$, s.d. 1.61) versus comparison $(M=2.12$, s.d. 1.54$)$ condition $(t(346)=19.80, P<0.001,95 \% \mathrm{CI}$ $3.01-3.67, d=2.12)$ and greater small-self feelings in the nature $(M=2.57$, s.d. $1.22)$ versus neutral $(M=1.79$, s.d. 1.15$)$ condition $(t(346)=6.17, P<0.001,95 \%$ CI $0.53-1.03, d=0.66)$. Unexpectedly, there was no difference in PA between conditions $\left(M_{\text {nature }}=2.96\right.$, s.d. 0.86 versus $M_{\text {comparison }}=2.81$, s.d. $0.91 ; t(346)=1.50$, $P=0.135,95 \% \mathrm{CI}-0.04$ to $0.33, d=0.16$ ), although the single-item assessment of happiness felt during the video was greater in the nature $(M=4.80$, s.d. 1.70$)$ than the comparison $(M=2.35$, s.d. 1.64) condition $(t(346)=13.67, P<0.001,95 \% \mathrm{CI}$ $2.10-2.80, d=1.47)$, supporting the reliability of the manipulation.

Study 6. Participants. Participants were 422 undergraduate students at Texas A\&M University (326 female, 94 male, 2 other or gender nonconforming) who participated in the study for partial completion of course requirements for an introductory psychology course. Ages in the sample ranged from 18 to 26 years ( $M=18.57$ years, s.d. 0.95 years). The majority of the sample was White (58.8\%), and $22.5 \%$ were Hispanic or Latinx.

Materials and procedure. Materials and procedures were identical to those of study 5 except for the inclusion of purpose and coherence items used in previous studies and the additional of exploratory measures described below. All participants completed the survey on laboratory computers in private cubicles. Replicating study 5 , the survey consisted of an awe manipulation followed by measures of EA $(M=5.83$, s.d. $0.75, \alpha=0.72)$, mattering $(M=5.40$, s.d. 1.29 , $\alpha=0.86)$, purpose $(M=5.76$, s.d. $1.04, \alpha=0.82)$, coherence $(M=5.00$, s.d. 1.04 , $\alpha=0.73)$, global MIL $(M=6.04$, s.d. $0.92, \alpha=0.84)$, small self $(M=2.19$, s.d. $1.18, \alpha=0.83)$ and $\operatorname{mood}(M=4.76$, s.d. $1.08, \alpha=0.92)$, as well as trait measures of gratitude $(M=6.11$, s.d. $0.79, \alpha=0.75)$ and mindfulness $(M=2.59$, s.d. 0.48 , $\alpha=0.81$ ) for exploratory purposes

Awe induction. Participants were randomly assigned to either an awe induction $\overline{\text { nature }(n=205})$ or comparison condition $(n=217)$. Again, in the nature condition, they watched the 2-min opening sequence of 'Planet Earth', whilst participants in the comparison condition watched a 2 -min instructional woodworking video. As in study 5 , participants also completed a manipulation check.

Manipulation check. We included a number of items specifically related to participants' experiences watching the videos. One of these items asked participants to indicate how much awe they experienced whilst watching the video on a scale from 1 ('I did not feel this at all') to 7 ('I felt this very intensely'). This item served as our manipulation check.

EA and meaning. The same five items applied in previous studies were used to assess EA $(M=5.83$, s.d. $0.75, \alpha=0.72)$, and the same three four-item scales were used to assess mattering $(M=5.40$, s.d. $1.29, \alpha=0.86)$, purpose $(M=5.76$, s.d. 1.04 $\alpha=0.82)$ and coherence $(M=5.00$, s.d. 1.04, $\alpha=0.73)$. Global MIL was measured with the four-item scale from Costin and Vignoles ${ }^{3}(M=6.04$, s.d. 0.92, $\alpha=0.84)$.

Mood. To assess current mood, we again asked participants to indicate how much they felt each of 12 positive emotions (for example, calm, happy; $M=4.76$, s.d.
1.08, $\alpha=0.92)$ right now ${ }^{49}$. They rated the intensity of emotion on a five-point scale (from 1 for 'very slightly or not at all' to 5 for 'extremely').

Small self. Six items assessing the experience of small self (for example, 'I felt insignificant in the grand scheme of things'; $M=2.19$, s.d. $1.18, \alpha=0.83$ ) were presented in random order and rated on a seven-point scale (from 1 for 'I did not feel this at all' to 7 for 'I felt this very intensely').

Exploratory measures. The 14-item Freiburg Mindfulness Inventory (for example, 'I am open to the experience of the present moment'; $M=2.59$, s.d. $0.48, \alpha=0.81$ ) was included and rated on a four-point scale (from 1 for 'rarely' to 4 for 'almost always') along with a measure of gratitude for exploratory purposes. Gratitude was measured via McCullough, Emmons, and Tsang's Gratitude questionnaire ${ }^{62}(M=6.11$, s.d. $0.79, \alpha=0.75$ ), which asked participants to rate six items (for example, 'I have so much in life to be thankful for') on a scale from 1 ('strongly disagree') to 7 ('strongly agree'). We included these two measures to examine whether our predicted effect might be accounted for by one or both of these two relevant constructs.

Manipulation effectiveness. Consistent with study 5, participants reported greater awe in the nature $(M=6.04$, s.d. 1.45$)$ than comparison $(M=2.09$, s.d. 1.51$)$ condition $(t(420)=27.48, P<0.001,95 \%$ CI 3.67-4.24, $d=2.68)$, and greater small-self feelings in the nature $(M=2.75$, s.d. 1.20) than comparison $(M=1.66$, s.d. 0.88$)$ condition $(t(420)=10.74, P<0.001,95 \%$ CI $0.89-1.29, d=1.05)$. Participants also reported greater PA in the nature $(M=4.99$, s.d. 1.09) than comparison $(M=4.54$, s.d. 1.02$)$ condition $(t(401)=4.31, P<0.001,95 \%$ CI $0.25-0.66, d=0.43)$.

Outliers. Further inspection of the dataset identified one extreme univariate outlier that was more than 5.9 s.d. away from the mean on the EA variable and 4.9 s.d. away from the mean on the global MIL variable. Excluding this outlier led to a larger difference between the two conditions on EA $(d=-0.29$ versus $d=-0.24)$ Excluding this outlier did not change the significance of any variable in the study for either the $t$ test analyses or the mediation analyses. For consistency with our pre-registration plan, we opted to report the results with this outlier included. However, we recommend that researchers should explicitly mention this exclusion criterion to account for extreme values on EA.

Study 7. Participants. We aimed to recruit approximately 400 participants. We first recruited as many participants as possible from the final 3 weeks of the Texas A\&M University subject pool $(n=345)$. These participants received partial completion of course requirements for an introductory psychology course. Because our college student sample was less than our target sample size, and consistent with our preregistration plan, we recruited a supplementary sample via Mturk prime $(n=211)$. These supplementary participants were paid 3 U.S. dollars to complete the study. We excluded participants who either indicated that they did not take the survey seriously $(n=73)$ or did not write about the specific writing topic $(n=10)$. After exclusions, our final merged sample consisted of 474 participants ( 251 female, 221 male, 2 other), aged from 18 to 71 years $(M=27.46$ years, s.d. 12.79 years). The sample was primarily White (79.1\%), and non-Hispanic (83.4\%).

Materials and procedure. Data for both samples were collected via online survey programmed in Qualtrics.

EA manipulation. Participants were randomly assigned to either the EA $(n=233)$ or control condition $(n=241)$. In each condition, participants were instructed that the experimenters were interested in how people describe different types of experience. They were then told that they were going to write about either an intrinsically valuable experience they had or a common place they visited, in the past week. We chose the control topic because recent research suggests routine experiences are associated with $\mathrm{MIL}^{63}$. By choosing this control topic, we hoped to mitigate the possibility that any differences in the dependent variables would be due to lowered ratings in the control condition, as opposed to higher ratings in the EA condition. After reading some information about each topic, participants were encouraged to spend a few minutes to try to bring forth a vivid image of the experience before they started writing. We further encouraged them to think about some specific questions when writing about the experience in an effort to increase the amount of time participants reflected on the experience (full prompts available at https://osf.io/4yx9p/)

Vividness of the event. Because vivid or easy-to-process imagery is linked to MIL ${ }^{64}$ we assessed the subjective ease of participants' imagery to rule out the possibility that the EA writing task was easier to imagine compared with the control topic. Specifically, we assessed this variable using two items, including 'How clear was the experience you wrote about?' and 'How easy was it to imagine the experience you wrote about?' $(M=4.51$, s.d. $0.65, r=0.46)$. Each item was rated on a scale from 1 ('not at all') to 5 ('extremely').

Global and tripartite MIL and EA. Participants then rated items similar to those used in study 4 to assess the extent to which the experience contributed to global 
MIL $(M=5.34$, s.d. $1.13, \alpha=0.69)$, mattering $(M=4.38$, s.d. $1.52, \alpha=0.82)$, purpose $(M=5.27$, s.d. $1.03, \alpha=0.56)$, coherence $(M=5.30$, s.d. $1.09, \alpha=0.73)$ and EA $(M=5.28$, s.d. $1.38, \alpha=0.90)$. These items were rated on a scale from 1 ('not at all') to 7 ('extremely').

Current mood. Finally, participants rated the extent to which they felt 12 positive $(M=4.67$, s.d. $1.25, \alpha=0.93)$ and 12 negative $(M=2.56$, s.d. 1.42 , $\alpha=0.93$ ) emotions 'currently' on a scale from 1 ('very slightly or not at all') to 7 ('extremely') ${ }^{49}$.

Manipulation effectiveness. Independent samples $t$ tests were conducted to test for an effect of the EA manipulation on global MIL and EA. As predicted, participants in the EA condition reported significantly greater levels of global $\operatorname{MIL}\left(M_{\mathrm{EA}}=5.76\right.$, s.d. 1.02 versus $M_{\text {control }}=4.93$, s.d. $1.09 ; t(472)=8.54, P<0.001$, $95 \%$ CI $0.64-1.02, d=0.78)$ and EA $\left(M_{\mathrm{EA}}=5.99\right.$, s.d. 0.90 versus $M_{\text {control }}=4.60$, s.d. $1.42 ; t(472)=12.73, P<0.001,95 \%$ CI $1.18-1.61, d=1.17)$, compared with the control condition. Whilst we had no specific predictions for our other meaning variables, $t$ tests similarly showed that participants in the EA condition reported greater levels of mattering $\left(M_{\mathrm{EA}}=4.96\right.$, s.d. 1.39 versus $M_{\text {control }}=3.81$, s.d. 1.43 ; $t(471)=8.88, P<0.001,95 \%$ CI $0.90-1.40, d=0.82)$, purpose $\left(M_{\mathrm{EA}}=5.58\right.$, s.d. 1.01 versus $M_{\text {control }}=4.97$, s.d. $0.96 ; t(472)=6.76, P<0.001,95 \%$ CI $0.43-0.79$, $d=0.62)$ and coherence $\left(M_{\mathrm{EA}}=5.59\right.$, s.d. 1.04 versus $M_{\text {control }}=5.02$, s.d. $1.07 ; t(472)$ $=5.80, P<0.001,95 \%$ CI $0.37-0.75, d=0.55)$, compared with those in the control condition. These later findings support the notion that each of these pathways to MIL are often interrelated. Finally, participants in the EA condition reported higher PA $\left(M_{\mathrm{EA}}=4.81\right.$, s.d. 1.26 versus $M_{\text {control }}=4.53$, s.d. $1.22 ; t(472)=2.42$, $P=0.016,95 \%$ CI $0.05-0.50, d=0.22)$ and lower NA $\left(M_{\mathrm{EA}}=2.42\right.$, s.d. 1.40 versus $M_{\text {control }}=2.70$, s.d. $1.42 ; t(472)=-2.15, P=0.032,95 \% \mathrm{CI}-0.53$ to $-0.02, d=0.20$ ), compared with those in the control condition, though these effects were relatively small. Finally, there were no differences between the conditions in the perceived vividness of the experience $\left(M_{\mathrm{FA}}=4.56\right.$, s.d. 0.64 versus $M_{\text {control }}=4.46$, s.d. 0.66 ; $t(472)=1.59, P=0.11,95 \% \mathrm{CI}-0.02$ to $0.21, d=0.15)$.

Reporting summary. Further information on research design is available in the Nature Research Reporting Summary linked to this article.

\section{Data availability}

Data, full materials and supplementary analyses for studies 2-7 can be found in Open Science Framework (OSF) at https://osf.io/4yx9p/. See notes in OSF for access information for materials and data in study 1 , as well as information about another large sample adult study (see 'MIDUS Study').

\section{Code availability}

As for data availability, all statistical code files including SPSS, Mplus and HLM are available in OSF at https://osf.io/4yx9p/.

Received: 6 August 2020; Accepted: 17 December 2021;

Published online: 10 February 2022

\section{References}

1. Frankl, V. E. The Doctor and the Soul: from Psychotherapy to Logotherapy (Vintage, 1986).

2. Hicks, J. A. \& King, L. A. Positive mood and social relatedness as information about meaning in life. J. Posit. Psychol. https://doi. org/10.1080/17439760903271108 (2009).

3. Costin, V. \& Vignoles, V. L. Meaning is about mattering: evaluating coherence, purpose, and existential mattering as precursors of meaning in life judgments. J. Personal. Soc. Psychol. https://doi.org/10.1037/ pspp0000225 (2020).

4. George, L. S. \& Park, C. L. The Multidimensional Existential Meaning Scale: a tripartite approach to measuring meaning in life. J. Posit. Psychol. https://doi. org/10.1080/17439760.2016.1209546 (2017).

5. Martela, F. \& Steger, M. F. The three meanings of meaning in life: distinguishing coherence, purpose, and significance. J. Posit. Psychol. https://doi.org/10.1080/17439760.2015.1137623 (2016).

6. Steger, M. F., Frazier, P., Oishi, S. \& Kaler, M. The meaning in life questionnaire: assessing the presence of and search for meaning in life. J. Couns. Psychol. https://doi.org/10.1037/0022-0167.53.1.80 (2006).

7. Heintzelman, S. J. \& King, L. A. Life is pretty meaningful. Am. Psychol. 69, 561-574 (2014).

8. Christy, A. G., Rivera, G., Chen, K. \& Hicks, J. A. in Positive Psychology: Established and Emerging Issues (ed. Dunn, D. S.) 220-235 (Routledge, 2017).

9. Krause, N. Religious meaning and subjective well-being in late life. J. Gerontol. B https://doi.org/10.1093/geronb/58.3.S160 (2003).

10. Reker, G. T., Peacock, E. J. \& Wong, P. T. Meaning and purpose in life and well-being: a life-span perspective. J. Gerontol. https://doi.org/10.1093/ geronj/42.1.44 (1987).
11. Ryff, C. D. \& Keyes, C. L. M. The structure of psychological well-being revisited. J. Personal. Soc. Psychol. https://doi.org/10.1037/0022-3514.69.4.719 (1995).

12. Steger, M. F., \& Kashdan, T. B. Stability and specificity of meaning in life and life satisfaction over one year. J. Happiness Stud. https://doi.org/10.1007/ s10902-006-9011-8 (2007).

13. Steger, M. F., Kawabata, Y., Shimai, S. \& Otake, K. The meaningful life in Japan and the United States: levels and correlates of meaning in life. J. Res. Personal. https://doi.org/10.1016/j.jrp.2007.09.003 (2008).

14. Zika, S. \& Chamberlain, K. On the relation between meaning in life and psychological well-being. Br. J. Psychol. https://doi. org/10.1111/j.2044-8295.1992.tb02429.x (1992).

15. Harlow, L. L., Newcomb, M. D., \& Bentler, P. M. Depression, self-derogation, substance use, and suicide ideation: lack of purpose in life as a mediational factor. J. Clin. Psychol. https://doi.org/10.1002/1097-4679(198601)42:1\%3C5::A ID-JCLP2270420102\%3E3.0.CO;2-9 (1986).

16. Klinger, E. in The Human Quest for Meaning: a Handbook of Psychological Research and Clinical Applications (eds. Wong P. T. P. \& Fry P. S.) 27-50 (Lawrence Erlbaum Associates, 1998).

17. Tanno, K. et al. Associations of ikigai as a positive psychological factor with all-cause mortality and cause-specific mortality among middle-aged and elderly Japanese people: findings from the Japan Collaborative Cohort Study. J. Psychosom. Res. https://doi.org/10.1016/j.jpsychores.2008.10.018 (2009).

18. Baumeister, R. F. Meanings of Life (Guilford Press, 1991).

19. Battista, J. \& Almond, R. The development of meaning in life. Psychiatry 36, 409-427 (1973)

20. Klinger, E. Meaning and Void: Inner Experience and the Incentives in People's Lives (Univ. of Minnesota Press, 1977).

21. McKnight, P. E., \& Kashdan, T. B. Purpose in life as a system that creates and sustains health and well-being: an integrative, testable theory. Rev. Gen. Psychol. https://doi.org/10.1037/a0017152 (2009).

22. Wong, P. T. in Meaning in Positive and Existential Psychology (eds. Batthyany, A. \& Russo-Netzer, P.) 149-184 (Springer, 2014).

23. de Muijnck, W. The meaning of lives and the meaning of things. J. Happiness Stud. https://doi.org/10.1007/s10902-012-9382-y (2013).

24. Frankl, V. E. Logotherapy and existentialism. Psychother-Theor. Res. https:// doi.org/10.1037/h0087982 (1967).

25. King, L. A. \& Hicks, J. A. Detecting and constructing meaning in life events. J. Posit. Psychol. https://doi.org/10.1080/17439760902992316 (2009).

26. Heintzelman, S. J., Trent, J. \& King, L. A. Encounters with objective coherence and the experience of meaning in life. Psychol. Sci. https://doi. org/10.1177/0956797612465878 (2013).

27. Kim, J. \& Hicks, J. A. Happiness begets children? Evidence for a bi-directional link between well-being and number of children. J. Posit. Psychol. https://doi. org/10.1080/17439760.2015.1025420 (2016).

28. Nelson, S. K. et al. In defense of parenthood: children are associated with more joy than misery. Psychol. Sci. https://doi.org/10.1177/0956797612447798 (2013).

29. Audi, R. Intrinsic value and meaningful life. Philos. Pap. https://doi. org $/ 10.1080 / 05568640509485162$ (2005).

30. King, L. A., Hicks, J. A., Krull, J. L. \& Del Gaiso, A. K. Positive affect and the experience of meaning in life. J. Personal. Soc. Psychol. https://doi. org/10.1037/0022-3514.90.1.179 (2006).

31. Hicks, J. A. \& King, L. A. Religious commitment and positive mood as information about meaning in life. J. Res. Personal. https://doi.org/10.1016/j. jrp.2007.04.003 (2008).

32. Hicks, J. A. \& King, L. A. Subliminal mere exposure and explicit and implicit positive affective responses. Cogn. Emot. https://doi.org/10.1080/02699931.201 0.497409 (2011)

33. Muthén, L. K. \& Muthén, B. O. Mplus User's Guide 8th edn (Muthén \& Muthén, 1998-2017).

34. Little, T. D., Rhemtulla, M., Gibson, K. \& Schoemann, A. M. Why the items versus parcels controversy needn't be one. Psychol. Method. https://doi. org/10.1037/a0033266 (2013).

35. Rosenthal, R., Rosnow, R. L. \& Rubin, D. B. Contrasts and Effect Sizes in Behavioral Research: a Correlational Approach (Cambridge Univ. Press, 2000).

36. Oishi, S., Lun, J., \& Sherman, G. D. Residential mobility, self-concept, and positive affect in social interactions. J. Personal. Soc. Psychol. https://doi. org/10.1037/0022-3514.93.1.131 (2007).

37. Hayes, A. Introduction to Mediation, Moderation, and Conditional Process Analysis (Guilford, 2018).

38. Preacher, K. J. \& Hayes, A. F. Asymptotic and resampling strategies for assessing and comparing indirect effects in multiple mediator models. Behav. Res. Methods. https://doi.org/10.3758/BRM.40.3.879 (2008).

39. Rivera, G. N., Vess, M., Hicks, J. A. \& Routledge, C. Awe and meaning: elucidating complex effects of awe experiences on meaning in life. Eur. J. Soc. Psychol. https://doi.org/10.1002/ejsp.2604 (2020).

40. Goodman, F. R., Disabato, D. J. \& Kashdan, T. B. Reflections on unspoken problems and potential solutions for the well-being juggernaut in positive psychology. J. Posit. Psychol. https://doi.org/10.1080/17439760.2020.1818815 (2020). 
41. George, L. S. \& Park, C. L. Are meaning and purpose distinct? An examination of correlates and predictors. J. Posit. Psychol. https://doi.org/10.1 080/17439760.2013.805801 (2013).

42. Rosenberg, M. \& McCullough, B. C. Mattering: inferred significance and mental health among adolescents. Res. Community Ment. Health 2, 163-182 (1981).

43. Carver, C. S. You want to measure coping but your protocol's too long: consider the brief COPE. Int. J. Behav. Med. https://doi.org/10.1207/ s15327558ijbm0401_6 (1997).

44. Butler, J. \& Kern, M. L. The PERMA-Profiler: a brief multidimensional measure of flourishing. Int. J. Wellbeing. https://doi.org/10.5502/ijw.v6i3.526 (2016)

45. Aust, F., Diedenhofen, B., Ullrich, S. \& Musch, J. Seriousness checks are useful to improve data validity in online research. Behav. Res. Methods. https://doi.org/10.3758/s13428-012-0265-2 (2013).

46. Schnell, T. The Sources of Meaning and Meaning in Life Questionnaire (SoMe): relations to demographics and well-being. J. Posit. Psychol. https:// doi.org/10.1080/17439760903271074 (2009).

47. Frankl, V. E. Man's Search for Meaning: an Introduction to Logotherapy (Pocket, 1963).

48. Weathers F. W. et al. PTSD Checklist for DSM-5 (PCL-5) (National Center for PTSD, 2013); www.ptsd.va.gov

49. Watson, D., Clark, L. A. \& Tellegen, A. Development and validation of brief measures of positive and negative affect: the PANAS scales. J. Personal. Soc. Psychol. https://doi.org/10.1037/0022-3514.54.6.1063 (1988).

50. Costello, A. B. \& Osborne, J. W. Best practices in exploratory factor analysis: four recommendations for getting the most from your analysis. Pract. Assess. Res. Evaluation. https://doi.org/10.7275/jyj1-4868 (2005).

51. Browne, M. W., \& Cudeck, R. Alternative ways of assessing model fit. Sociol. Method. Res. https://doi.org/10.1177/0049124192021002005 (1992).

52. Brown, T. A. Confirmatory Factor Analysis for Applied Research (Guilford Press, 2015).

53. Hu, L. T. \& Bentler, P. M. Cutoff criteria for fit indexes in covariance structure analysis: conventional criteria versus new alternatives. Struct. Equ. Modeling. https://doi.org/10.1080/10705519909540118 (1999).

54. Byrne, B. M., Shavelson, R. J. \& Muthén, B. Testing for the equivalence of factor covariance and mean structures: the issue of partial measurement invariance. Psychol. Bull. https://doi.org/10.1037/0033-2909.105.3.456 (1989).

55. Kray, L. J. et al. From what might have been to what must have been: counterfactual thinking creates meaning. J. Personal. Soc. Psychol. https://doi. org/10.1037/a0017905 (2010)

56. Heintzelman, S. J. \& King, L. A. (The feeling of) meaning-as-information. Personal. Soc. Psychol. Rev. https://doi.org/10.1177/1088868313518487 (2014).

57. Waytz, A., Hershfield, H. E. \& Tamir, D. I. Mental simulation and meaning in life. J. Personal. Soc. Psychol. https://doi.org/10.1037/a0038322 (2015).

58. Valdesolo, P. \& Graham, J. Awe, uncertainty, and agency detection. Psychol. Sci. https://doi.org/10.1177/0956797613501884 (2014).
59. Piff, P. K. et al. Awe, the small self, and prosocial behavior. J. Personal. Soc. Psychol. https://doi.org/10.1037/pspi0000018 (2015).

60. Gordon, A. M. et al. The dark side of the sublime: distinguishing a threat-based variant of awe. J. Personal. Soc. Psychol. https://doi.org/10.1037/ pspp0000120 (2017).

61. Rudd, M., Vohs, K. D. \& Aaker, J. Awe expands people's perception of time, alters decision making, and enhances well-being. Psychol. Sci. https://doi. org/10.1177/0956797612438731 (2012).

62. McCullough, M. E., Emmons, R. A. \& Tsang, J.-A. The grateful disposition: a conceptual and empirical topography. J. Personal. Soc. Psychol. https://doi. org/10.1037/0022-3514.82.1.112 (2002).

63. Heintzelman, S. J. \& King, L. A. Routines and meaning in life. Person. Soc. Psychol. Bull. https://doi.org/10.1177/0146167218795133 (2019).

64. Schlegel, R. J., Hicks, J. A., King, L. A. \& Arndt, J. Feeling like you know who you are: perceived true self-knowledge and meaning in life. Person. Soc. Psychol. Bull. https://doi.org/10.1177/0146167211400424 (2011).

\section{Acknowledgements}

None of these studies were supported by funding sources. We thank B. Schmeichel, M. Vess and $\mathrm{K}$. McLean for comments on a previous version of this manuscript.

\section{Author contributions}

J.A.H., P.H., Z.L., R.J.S., J.K. and F.M. contributed to the conception of the core research idea and at least one study design. J.A.H., P.H., R.J.S., J.K. and C.S. performed analysis and interpreted data. J.A.H., P.H., R.J.S., J.K., C.S. and F.M. prepared the manuscript. N.E. and D.F.C. collected and preprocessed the data from study 1. H.Z. collected and preprocessed the data from study 2 , sample B. All authors approved the final version of this manuscript.

\section{Competing interests}

The authors declare no competing interests.

\section{Additional information}

Extended data is available for this paper at https://doi.org/10.1038/s41562-021-01283-6. Supplementary information The online version contains supplementary material available at https://doi.org/10.1038/s41562-021-01283-6.

Correspondence and requests for materials should be addressed to Joshua A. Hicks. Peer review information Nature Human Behaviour thanks Vlad Costin and the other, anonymous, reviewer(s) for their contribution to the peer review of this work.

Reprints and permissions information is available at www.nature.com/reprints. Publisher's note Springer Nature remains neutral with regard to jurisdictional claims in published maps and institutional affiliations.

(c) The Author(s), under exclusive licence to Springer Nature Limited 2022 


\section{NATURE HUMAN BEHAVIOUR}

\begin{tabular}{lcccccc}
\hline \multicolumn{1}{c}{ Predictor } & $B$ & $S E$ & $\beta$ & $t$ & $p$ & $95 \% \mathrm{Cl}$ \\
\hline Intercept & 1.01 & .06 & & 16.38 & $<.001$ & {$[.88,1.13]$} \\
Age & .01 & .001 & .06 & 8.03 & $<.001$ & {$[.004, .01]$} \\
Gender & .06 & .02 & .02 & 2.72 & .006 & {$[.02, .10]$} \\
LA & .26 & .01 & .32 & 33.51 & $<.001$ & {$[.24, .27]$} \\
Mattering & .16 & .01 & .17 & 18.06 & $<.001$ & {$[.14, .18]$} \\
Purpose & .16 & .01 & .22 & 22.91 & $<.001$ & {$[.14, .17]$} \\
Coherence & .04 & .01 & .02 & 2.77 & .006 & {$[.01, .06]$} \\
\hline
\end{tabular}

Extended Data Fig. 1 | Meaning relevant coping strategies during the COVID-19 pandemic predicting global meaning in life in Study 1. LA = Life appreciation. 


\begin{tabular}{lccc}
\hline \multicolumn{1}{c}{ Item } & $M$ & $S D$ & Factor loading \\
\hline 1. I have great appreciation for the beauty of life. & 5.89 & 1.10 & .83 \\
5. I appreciate a wide variety of experiences. & 5.83 & 1.03 & .81 \\
7. I appreciate the little things in life. & 5.91 & 1.00 & .76 \\
3. I take great interest in my daily activities. & 5.13 & 1.29 & .75 \\
12. I tend to find myself deeply engaged in conversations with other people. & 5.34 & 1.40 & .75 \\
\hline
\end{tabular}

Extended Data Fig. 2 | Exploratory factor analysis: Rotated pattern matrix of experiential appreciation scale in Study 2. Sample A: $n=469$. 


\section{NATURE HUMAN BEHAVIOUR}

ARTICLES

\begin{tabular}{lcccccccc}
\hline \multicolumn{1}{c}{ Measure } & 1 & 2 & 3 & 4 & 5 & 6 & 7 & 8 \\
\hline 1. Global MIL & - & -.27 & .48 & .74 & .65 & .54 & .50 & -.36 \\
2. Crisis/COVID-19 stress & -.80 & - & -.21 & -.25 & -.16 & -.28 & -.19 & .50 \\
3. EA & .64 & -.56 & - & .31 & .37 & .36 & .51 & -.13 \\
4. Mattering & .70 & -.60 & .52 & - & .52 & .36 & .36 & -.29 \\
5. Purpose & .63 & -.59 & .55 & .50 & - & .48 & .41 & -.28 \\
6. Coherence & .60 & -.58 & .56 & .51 & .56 & - & .35 & -.25 \\
7. PA & .55 & -.57 & .56 & .45 & .47 & .54 & - & -.34 \\
8. NA & -.41 & .49 & -.31 & -.33 & -.32 & -.47 & -.43 & - \\
\hline
\end{tabular}

Extended Data Fig. 3 | Bivariate correlations among study variables in Study 2. MIL=meaning in life. $E A=$ experiential appreciation. $P A=$ positive affect. $N A=$ negative affect. Correlation coefficients and descriptive statistics below the diagonal represent Sample A; those above the diagonal represent Sample B. All correlation coefficients are statistically significant at $p<.001$, except for the correlations between COVID-19-related stress and purpose at $p=.006$, and PA at $p=.001$ and the correlation between EA and NA at $p=.032$ for Sample B. 


\begin{tabular}{|c|c|c|c|c|c|c|c|}
\hline Measure & 1 & 2 & 3 & 4 & 5 & 6 & 7 \\
\hline 1. Current MIL & - & & & & & & \\
\hline 2. $E A$ & .35 & - & & & & & \\
\hline 3. Mattering & .27 & .30 & - & & & & \\
\hline 4. Purpose & .33 & .35 & .33 & - & & & \\
\hline 5. Coherence & .32 & .34 & .31 & .44 & - & & \\
\hline 6. PA & .40 & .48 & .27 & .34 & .34 & - & \\
\hline 7. NA & -.39 & -.38 & -.21 & -.27 & -.33 & -.42 & - \\
\hline
\end{tabular}

Extended Data Fig. 4 | Within-person correlations between study variables in Study 3. MIL = meaning in life. EA=experiential appreciation. PA = positive affect. NA = negative affect. 
Example narratives

The event was my organization's semi-formal. It was meaningful to me because I spent time with some of my closest friends and just got to enjoy their company.

I went to see a special needs talent show this week that my friend put on. She put so much work into it so it was so fun to support her. and watching special needs kids feel loved and celebrated brings joy to my heart and provides me with new perspective.

I spent a day last weekend with two close friends just watching a show, hanging out, and eating snacks. It was not much but it was one of the best days in a while. It was meaningful because we laughed and shared stories and just enjoyed each other's company. Everyone was very in the moment and was just having a happy time.

Recently my uncle passed away and his son, my cousin held a birthday party for himself. He gave a speech saying thank you to all of us for being there and that's all he wanted for his birthday. For us to be together creating memories because he knew that my uncle would have loved it.

The event that stands out as the most meaningful to me from the past week is having a boyfriend spend the weekend in College Station with me. This was the most meaningful thing from the week because I've never spent a weekend with someone in my apartment before so it just made me feel a sense of independence and being grown to show someone my place where I live with a roommate and no family. It also was a new experience to spend that much uninterrupted time with someone, so I learned what that was like which made it meaningful compared to other events throughout the week.

Extended Data Fig. 5 | Examples of meaningful experiences rated high in experiential appreciation and relatively low in mattering, purpose, and coherence in Study 4. 


\begin{tabular}{|c|c|c|c|c|c|c|}
\hline Measure & 1 & 2 & 3 & 4 & 5 & 6 \\
\hline 1. Global MIL & - & & & & & \\
\hline 2. $E A$ & .68 & - & & & & \\
\hline 3. Mattering & .72 & .59 & - & & & \\
\hline 4. Small self & -.19 & -.20 & -.24 & - & & \\
\hline 5. PA & .52 & .47 & .38 & .06 & - & \\
\hline 6. NA & -.34 & -.34 & -.33 & .39 & -.19 & - \\
\hline
\end{tabular}

Extended Data Fig. 6 | Bivariate correlations among key variables in Study 5. MIL=meaning in life. EA= experiential appreciation. PA = positive affect. $\mathrm{NA}=$ negative affect. All correlation coefficients are statistically significant at $p<.001$, except for the correlation between small self and global MIL at $p<.01$, and the non-significant correlation between PA and small self. 
a
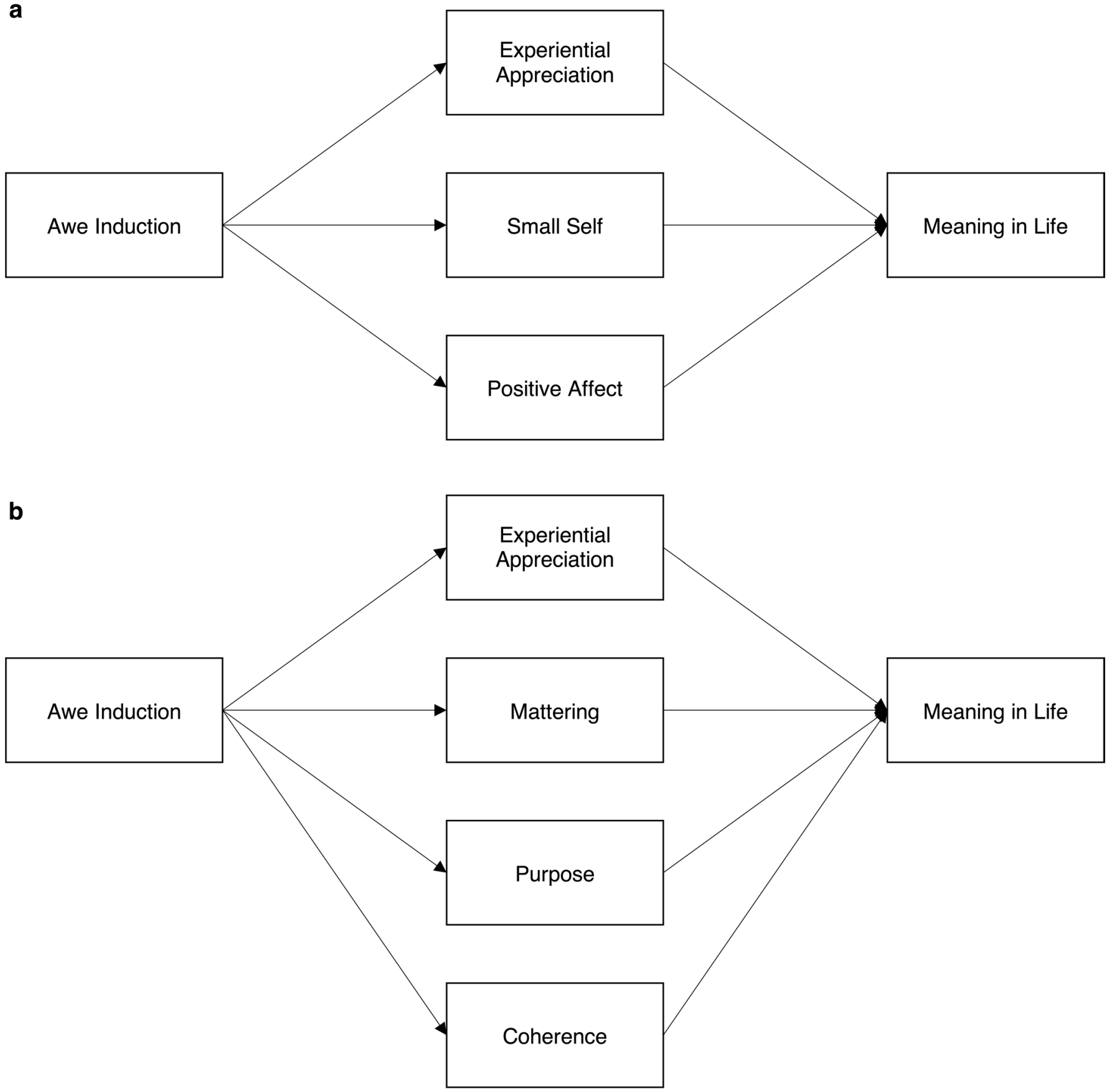

Extended Data Fig. 7 | Conceptual model for indirect effects of awe induction on meaning in life. a, Experiential aprreciation, small Self, and positive affect as mediators. b, Experiential aprreciation and tripartite components of meaning as mediators. The latter model and its modified one were used in Studies 5 and 6. 


\begin{tabular}{|c|c|c|c|c|c|c|c|}
\hline Measure & 1 & 2 & 3 & 4 & 5 & 6 & 7 \\
\hline 1. Global MIL & - & & & & & & \\
\hline 2. $E A$ & .61 & - & & & & & \\
\hline 3. Mattering & .76 & .50 & - & & & & \\
\hline 4. Purpose & .56 & .48 & .45 & - & & & \\
\hline 5. Coherence & .56 & .41 & .47 & .55 & - & & \\
\hline 6. Small self & -.16 & -.04 & -.14 & -.15 & -.23 & - & \\
\hline 7. PA & .38 & .38 & .34 & .31 & .41 & .01 & - \\
\hline
\end{tabular}

Extended Data Fig. 8 | Bivariate correlations among key variables in Study 6. MIL=meaning in life. EA = experiential appreciation. PA=positive affect. All correlation coefficients are statistically significant at $p<.001$, except for the correlation between small self and global MIL, small self and mattering, and small self and purpose at $p<.01$, and the non-significant correlations between small self and EA and PA and small self. 


\section{NATURE HUMAN BEHAVIOUR}

\begin{tabular}{|c|c|c|c|c|c|c|c|c|}
\hline Measure & 1 & 2 & 3 & 4 & 5 & 6 & 7 & 8 \\
\hline 1. Global MIL & - & & & & & & & \\
\hline 2. $E A$ & .62 & - & & & & & & \\
\hline 3. Mattering & .63 & .64 & - & & & & & \\
\hline 4. Purpose & .56 & .48 & .47 & - & & & & \\
\hline 5. Coherence & .53 & .46 & .47 & .70 & - & & & \\
\hline 6. PA & .39 & .35 & .33 & .29 & .28 & - & & \\
\hline 7. NA & -.36 & -.08 & -.15 & -.40 & -.38 & -.45 & - & \\
\hline 8. Vividness & .27 & .14 & .10 & .24 & .31 & .15 & -.25 & - \\
\hline
\end{tabular}

Extended Data Fig. 9 | Bivariate correlations among key variables in Study 7. MIL=meaning in life. $E A=$ experiential appreciation. $P A=$ positive affect. $N A=$ negative affect. All correlation coefficients are statistically significant at $p<.001$, except for the correlation between NA and mattering, vividness and $\mathrm{EA}$, and vividness and PA at $p<.01$, the correlation between vividness and mattering at $p<.05$, and the non-significant correlation between NA and EA. 


\section{Reporting Summary}

Nature Portfolio wishes to improve the reproducibility of the work that we publish. This form provides structure for consistency and transparency in reporting. For further information on Nature Portfolio policies, see our Editorial Policies and the Editorial Policy Checklist.

\section{Statistics}

For all statistical analyses, confirm that the following items are present in the figure legend, table legend, main text, or Methods section.

n/a Confirmed

$\bigotimes$ The exact sample size $(n)$ for each experimental group/condition, given as a discrete number and unit of measurement

$\bigotimes$ A statement on whether measurements were taken from distinct samples or whether the same sample was measured repeatedly

$\varnothing$ The statistical test(s) used AND whether they are one- or two-sided

Only common tests should be described solely by name; describe more complex techniques in the Methods section.

$\bigotimes$ A description of all covariates tested

\A description of any assumptions or corrections, such as tests of normality and adjustment for multiple comparisons

$\square$ A full description of the statistical parameters including central tendency (e.g. means) or other basic estimates (e.g. regression coefficient)

$\triangle$ AND variation (e.g. standard deviation) or associated estimates of uncertainty (e.g. confidence intervals)

$X$ For null hypothesis testing, the test statistic (e.g. $F, t, r$ ) with confidence intervals, effect sizes, degrees of freedom and $P$ value noted

$\triangle$ Give P values as exact values whenever suitable.

Х $\square$ For Bayesian analysis, information on the choice of priors and Markov chain Monte Carlo settings

$\square(X$ For

$\triangle$ For hierarchical and complex designs, identification of the appropriate level for tests and full reporting of outcomes

$\bigotimes$ Estimates of effect sizes (e.g. Cohen's $d$, Pearson's $r$ ), indicating how they were calculated

Our web collection on statistics for biologists contains articles on many of the points above.

\section{Software and code}

Policy information about availability of computer code

\section{Data collection Qualtrics}

Data analysis SPSS, Mplus, HLM

For manuscripts utilizing custom algorithms or software that are central to the research but not yet described in published literature, software must be made available to editors and reviewers. We strongly encourage code deposition in a community repository (e.g. GitHub). See the Nature Portfolio guidelines for submitting code \& software for further information.

\section{Data}

Policy information about availability of data

All manuscripts must include a data availability statement. This statement should provide the following information, where applicable:

- Accession codes, unique identifiers, or web links for publicly available datasets

- A description of any restrictions on data availability

- For clinical datasets or third party data, please ensure that the statement adheres to our policy 


\section{Field-specific reporting}

Please select the one below that is the best fit for your research. If you are not sure, read the appropriate sections before making your selection.

$\square$ Life sciences $\quad$ Behavioural \& social sciences $\square$ Ecological, evolutionary \& environmental sciences

For a reference copy of the document with all sections, see nature.com/documents/nr-reporting-summary-flat.pdf

\section{Behavioural \& social sciences study design}

All studies must disclose on these points even when the disclosure is negative.

Study description

All studies were quantitative, including correlation studies (Studies 1-4) and experiments (Studies 5-7). Across the experiments, we compared two conditions.

Research sample

Participants were undergraduate students at Texas A\&M University, except for those in Study 1 (public data set), for Sample B in Study 2 (Chinese college students), and in Study 7 (MTurkers). Details can be found in the paper.

Sampling strategy

Describe the sampling procedure (e.g. random, snowball, stratified, convenience). Describe the statistical methods that were used to predetermine sample size OR if no sample-size calculation was performed, describe how sample sizes were chosen and provide a rationale for why these sample sizes are sufficient. For qualitative data, please indicate whether data saturation was considered, and what criteria were used to decide that no further sampling was needed.

Data collection All data for Studies 2-7 were collected through Qualtrics.

Timing

Indicate the start and stop dates of data collection. If there is a gap between collection periods, state the dates for each sample cohort.

Data exclusions

In some studies, we excluded data based on a priori data exclusion criteria (e.g., failing to pass attention check items). Details can be found in the paper.

Non-participation

State how many participants dropped out/declined participation and the reason(s) given OR provide response rate OR state that no participants dropped out/declined participation.

Randomization

In all experiments, we randomly assigned participants into the conditions.

\section{Reporting for specific materials, systems and methods}

We require information from authors about some types of materials, experimental systems and methods used in many studies. Here, indicate whether each material, system or method listed is relevant to your study. If you are not sure if a list item applies to your research, read the appropriate section before selecting a response.

Materials \& experimental systems

$\mathrm{n} / \mathrm{a}$ Involved in the study

\ $\square$ Antibodies

$\bigotimes \square$ Eukaryotic cell lines

$\bigotimes \square$ Palaeontology and archaeology

Х $\square$ Animals and other organisms

$\square$ \uman research participants

$\bigotimes \square$ Clinical data

$\triangle \square$ Dual use research of concern
Methods

\begin{tabular}{r|l}
\hline n/a & Involved in the study \\
$\square$ & $\square$ ChIP-seq \\
$\square$ & $\square$ Flow cytometry \\
$\square$ & $\square$ MRI-based neuroimaging
\end{tabular}

\section{Human research participants}

Policy information about studies involving human research participants

Population characteristics

Recruitment

Ethics oversight
See above

Describe how participants were recruited. Outline any potential self-selection bias or other biases that may be present and how these are likely to impact results.

The IRB at Texas A\&M University approved the study protocol. 